Supporting Information

\title{
Synthesis of Branched Octahydro-Indene with Methyl Benzaldehyde and Methyl Isobutyl Ketone
}

Xiaojun Zhang, ${ }^{\dagger, \#}$ Fengan Han, ${ }^{\dagger,}, * \#$ Songzhu Lin,${ }^{\dagger}$ Fang Chen, ${ }^{\ddagger}$ Mojie Sun, ${ }^{\dagger}$ Jianjun

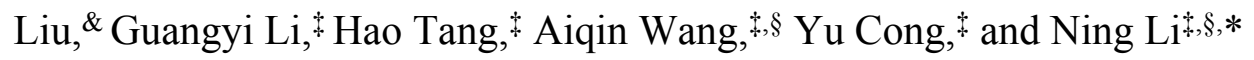

† Sci-Tech Center for Clean Conversion and High-valued Utilization of Biomass, Northeast Electric Power University, No. 169 Changchun Road, Jilin 132012, China.

$\$$ CAS Key Laboratory of Science and Technology on Applied Catalysis, Dalian Institute of Chemical Physics, Chinese Academy of Sciences, Dalian 116023, China.

\& State Key Laboratory of High Performance Ceramics and Superfine Microstructure, Shanghai institute of Ceramics, Chinese Academy of Sciences, 1295 Dingxi Road, Shanghai 200050, China

$\S$ Dalian National Laboratory for Clean Energy, No. 457 Zhongshan Road, Dalian 116023, China.

\# These authors contributed equally to this work.

The number of pages: 46

The number of figures: 40

The number of tables: 1

*Corresponding author: Ning Li, Tel.:+86-411-84379738,E-mail: lining@dicp.ac.cn 


\section{Characterization}

\section{1. $N_{2}$-adsorption}

The specific BET surface areas $\left(\mathrm{S}_{\mathrm{BET}}\right)$ of the catalysts were measured by nitrogen adsorption at $77 \mathrm{~K}$ using an ASAP 2010 apparatus. Before the measurements, the catalysts were pretreated at $573 \mathrm{~K}$ for $4 \mathrm{~h}$.

\section{2. $\mathrm{CO}_{2}-\mathrm{TPD}$}

The basicity of the solid-base catalysts used in aldol condensation was characterized by $\mathrm{CO}_{2}$-temperature-programmed desorption $\left(\mathrm{CO}_{2}-\mathrm{TPD}\right)$ that was carried out by a Micrometeritics AutoChem II 2920 Automated Catalyst Characterization System. For each test, $0.1 \mathrm{~g}$ of catalyst was used. The catalyst was put into a quartz reactor, pretreated in He flow at its preparation temperature for $1 \mathrm{~h}$ and cooled down in He flow to $353 \mathrm{~K}$. After the saturated adsorption of $\mathrm{CO}_{2}$ at that temperature, the catalyst was heated in He flow at $353 \mathrm{~K}$ for $30 \mathrm{~min}$ (to remove the physically adsorbed $\mathrm{CO}_{2}$ ). After the stabilization of baseline, the catalyst was heated in He flow from 353 to $1073 \mathrm{~K}$ at a rate of $10 \mathrm{~K} \mathrm{~min}^{-1}$. The desorption of $\mathrm{CO}_{2}$ were analyzed by the OminiStar mass spectrometer (MS) that was equipped with the software quadstar 32-bit.

\section{3. $\mathrm{NH}_{3}-\mathrm{TPD}$}

The acidity of the solid-base catalysts used in aldol condensation was analyzed by $\mathrm{NH}_{3}$-temperature-programmed desorption $\left(\mathrm{NH}_{3}\right.$-TPD) that was conducted by a Micrometeritics AutoChem II 2920 Automated Catalyst Characterization System. For 
each analysis, $0.1 \mathrm{~g}$ of catalyst was used. The catalyst was put into a quartz reactor, pretreated in He flow at $393 \mathrm{~K}$ for $2 \mathrm{~h}$ and cooled down in He flow to $373 \mathrm{~K}$. After the saturated adsorption of $\mathrm{NH}_{3}$ at that temperature, the catalyst was heated in $\mathrm{He}$ flow at $373 \mathrm{~K}$ for $30 \mathrm{~min}$ to remove the physically adsorbed $\mathrm{NH}_{3}$. After the stabilization of baseline, the catalyst was heated in He flow from 373 to $1073 \mathrm{~K}$ at a rate of $10 \mathrm{~K}$ $\min ^{-1}$. The desorption of $\mathrm{NH}_{3}$ were analyzed by the OminiStar mass spectrometer that was equipped with the software quadstar 32-bit.

\section{ICP-AES}

The $\mathrm{K}$ (or $\mathrm{Na}$ ) contents in the fresh and used catalysts were measured by an inductively coupled plasma-atomic emission spectrometry (ICP-AES). To do this, the samples were first solved by acid solutions. The concentrations of $\mathrm{K}$ (or $\mathrm{Na}$ ) in the samples were measured using ICP-OES (Perkin-Elmer Optima 7300DV). 


\section{Calibration equations for the calculation of aldol condensation products}

In this work, the masses of aldol condensation products were measured by GC using dodecane as internal standard. According to our calibration (see Figure S40), the equations for the calculation of unreacted methyl benzaldehyde and aldol condensation products were listed below:

Mass of unreacted 2-methyl benzaldehyde $=[0.01966+1.16747 \times($ peak area of 2-methyl benzaldehyde/peak area of dodecane)]× mass of dodecane standard Mass of unreacted 4-methyl benzaldehyde $=[0.02621+1.17733 \times($ peak area of 4-methyl benzaldehyde/peak area of dodecane)]× mass of dodecane standard Mass of $\mathbf{1 A}=[0.00555+1.15131 \times($ peak area of $\mathbf{1 A} /$ peak area of dodecane $)] \times$ mass of dodecane standard Mass of $\mathbf{2 A}=[1.18936 \times($ peak area of $\mathbf{2 A} /$ peak area of dodecane $)-0.01833] \times$ mass of dodecane standard

Mass of $\mathbf{3 A}=[0.01063+1.15751 \times($ peak area of $\mathbf{3 A} /$ peak area of dodecane $)] \times$ mass of dodecane standard

Mass of $\mathbf{4 A}=[0.02001+1.11768 \times($ peak area of $\mathbf{4 A} /$ peak area of dodecane $)] \times$ mass of dodecane standard Mass of $\mathbf{5 A}=[1.079 \times($ peak area of $\mathbf{5 A} /$ peak area of dodecane $)-0.00081971] \times$ mass of dodecane standard Mass of $\mathbf{6 A}=[0.00146+1.12368 \times($ peak area of $\mathbf{6 A} /$ peak area of dodecane $)] \times$ mass of dodecane standard 
Table S1. Densities and Freezing Points of the Jet Fuel Range $C_{10}-C_{16}$ Polycycloalkanes Synthesized by the Aldol Condensation of Lignocellulosic Platform Compounds Followed by Hydrodeoxygenation.

\begin{tabular}{|c|c|c|c|}
\hline Polycycloalkane & Density $\left(\mathrm{g} \mathrm{mL}^{-1}\right)$ & Freezing point $(\mathrm{K})$ & Reference \\
\hline & 0.867 & 235.0 & 1 \\
\hline & 0.918 & - & 2 \\
\hline & 0.887 & 274.2 & 1 \\
\hline & 0.87 & 228.7 & 3 \\
\hline & 0.99 & 251.0 & 4 \\
\hline & 0.96 & 270.0 & 4 \\
\hline
\end{tabular}




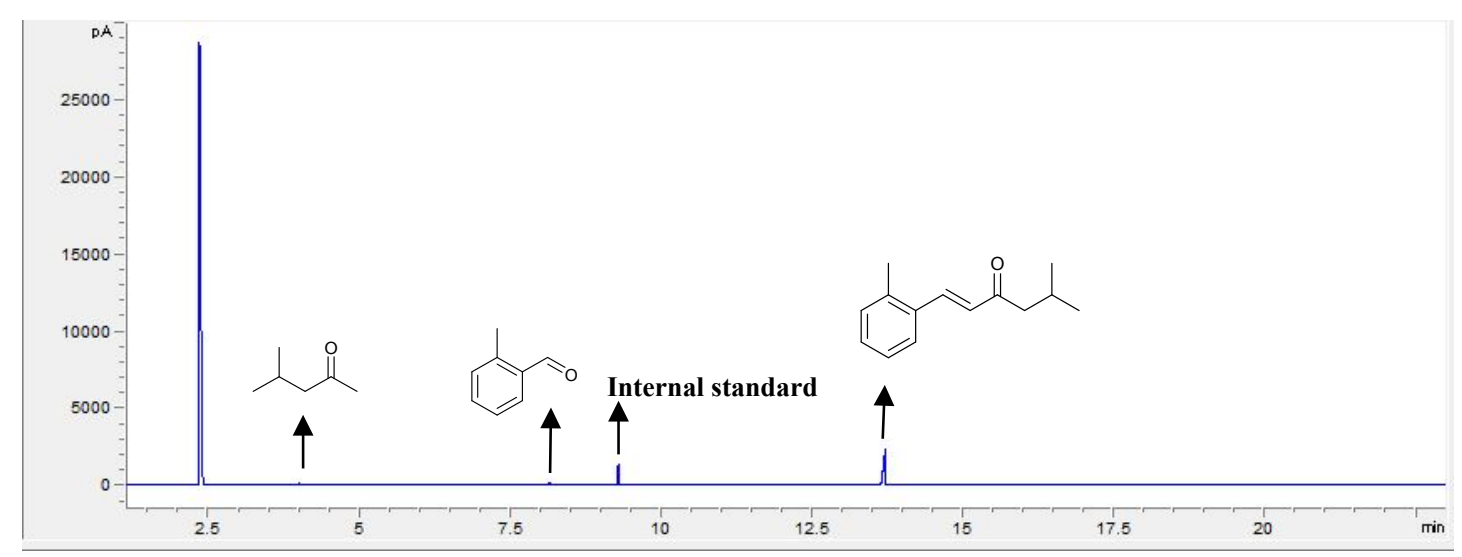

Figure S1. Gas chromatogram of the aldol condensation product of 2-methyl benzaldehyde and MIBK. Reaction conditions: 10 mmol MIBK, 10 mmol 2-methyl benzaldehyde, $0.2 \mathrm{~g} \mathrm{~K}_{2} \mathrm{CO}_{3} / \mathrm{Al}_{2} \mathrm{O}_{3}$ catalyst; $403 \mathrm{~K}, 6$ h. 


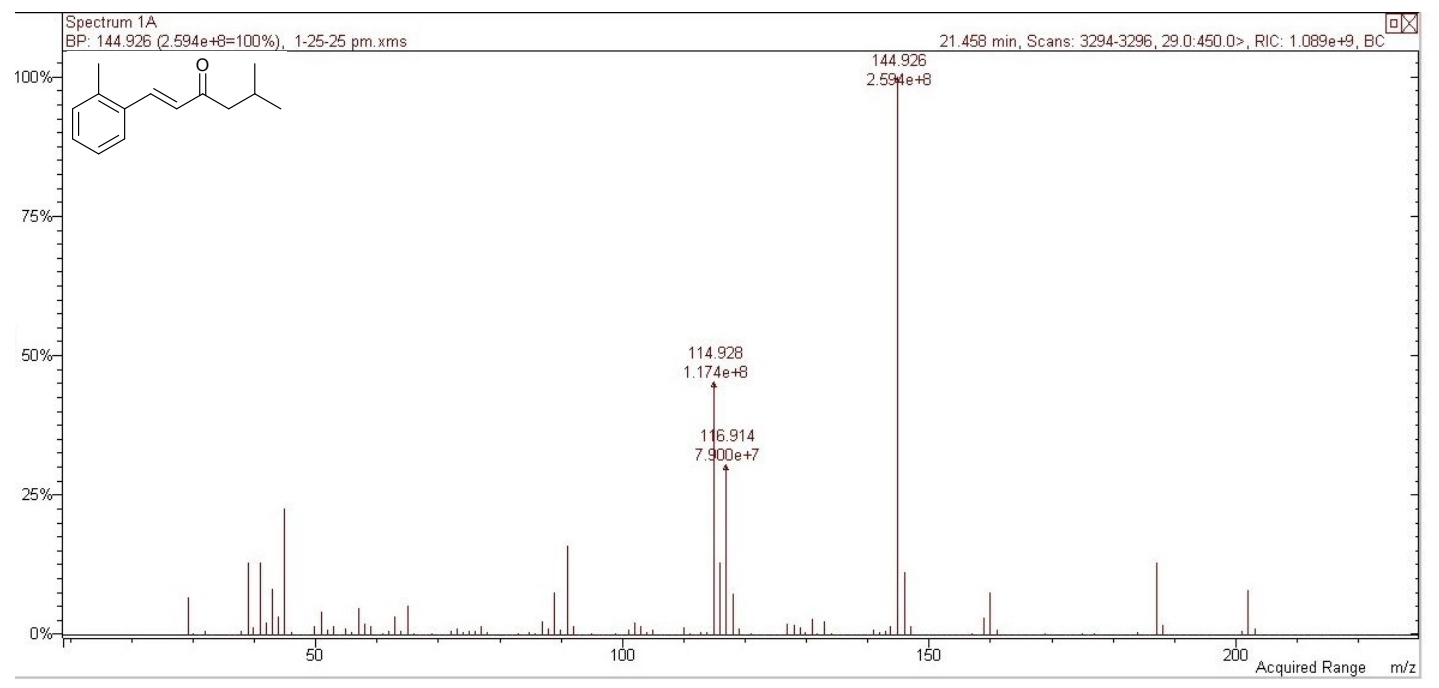

Figure S2. Mass spectrogram of the 1A from the aldol condensation of 2-methyl benzaldehyde and MIBK. 

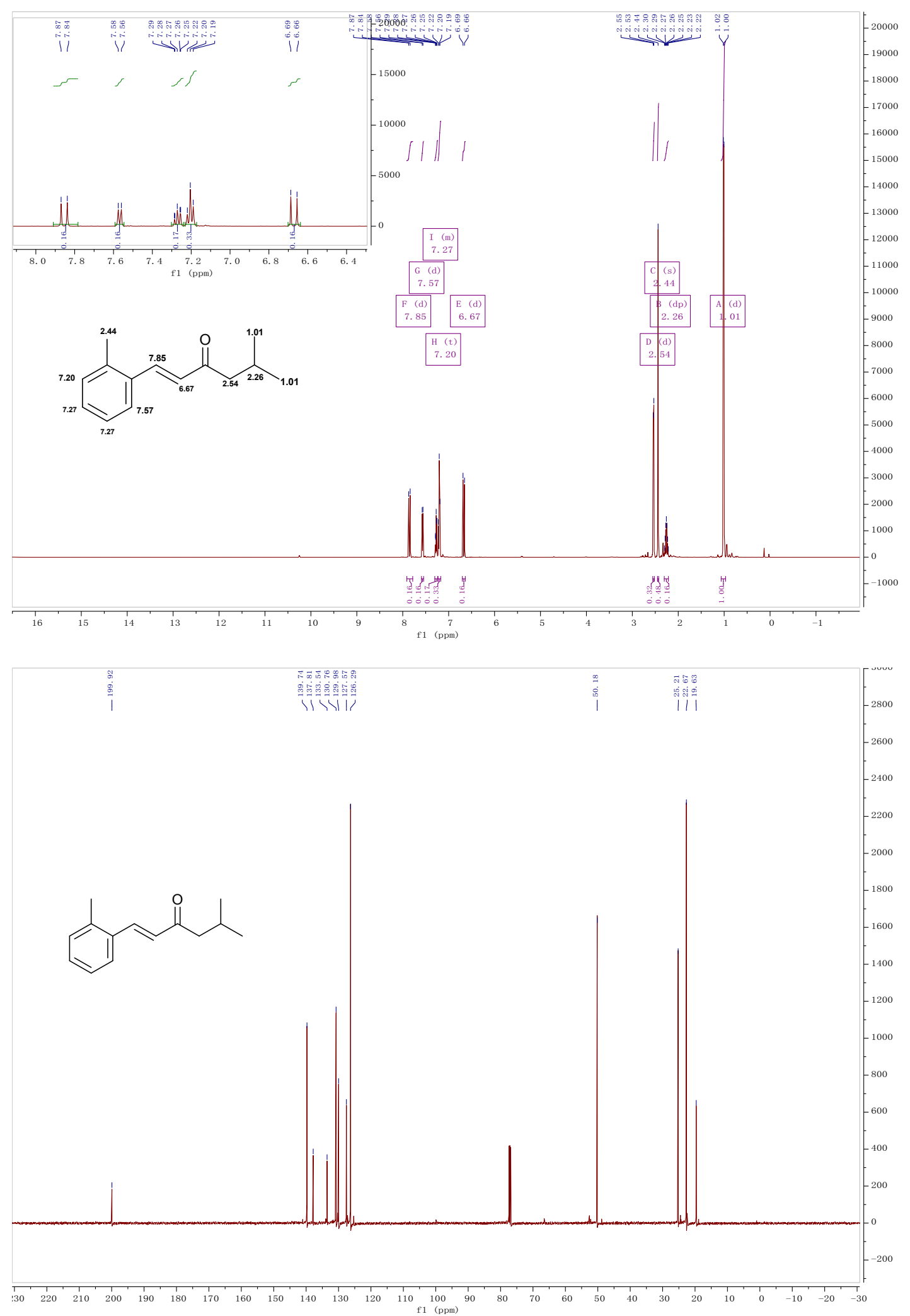

Figure S3. ${ }^{1} \mathrm{H}-\mathrm{NMR}$ and ${ }^{13} \mathrm{C}$-NMR spectra of the $\mathbf{1 A}$ from the aldol condensation of 2-methyl benzaldehyde and MIBK. 


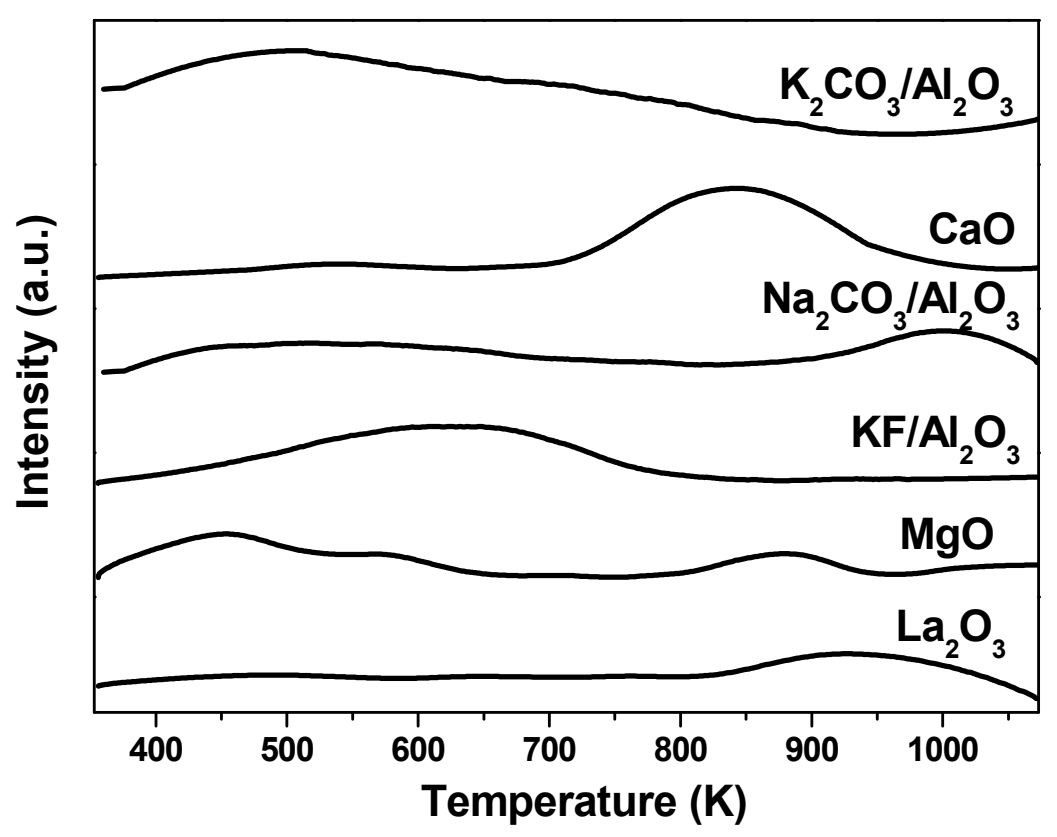

Figure S4. $\mathrm{CO}_{2}$-TPD profiles of different solid base catalysts. 


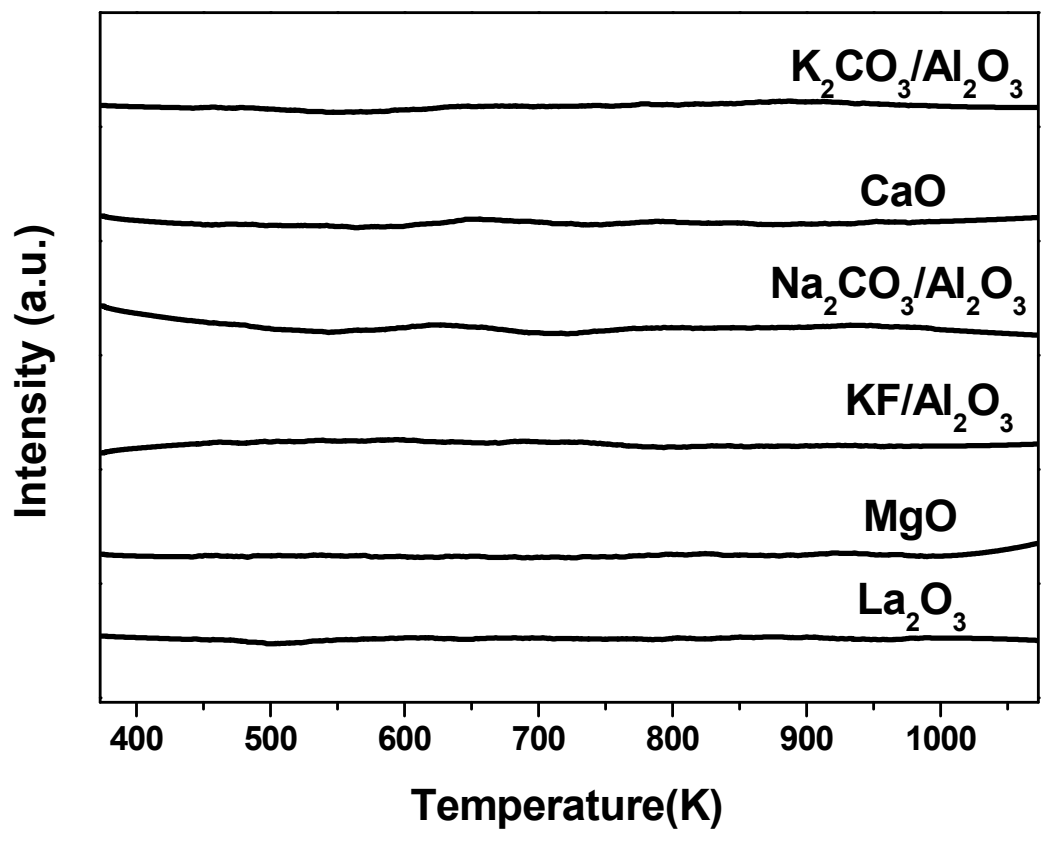

Figure S5. $\mathrm{NH}_{3}-\mathrm{TPD}$ profiles of different solid base catalysts. 


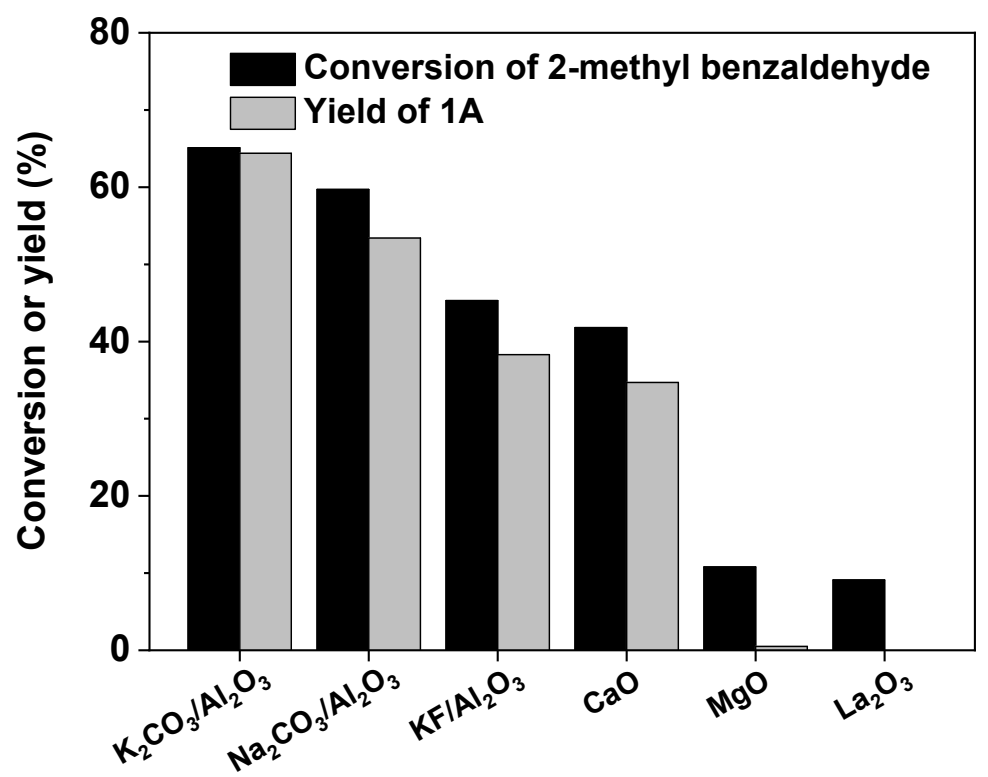

Figure S6. 2-Methyl benzaldehyde conversions and 1A yields over solid bases.

Reaction conditions: $10 \mathrm{mmol}$ MIBK, $10 \mathrm{mmol}$ 2-methyl benzaldehyde, $0.2 \mathrm{~g}$ catalyst; $393 \mathrm{~K}, 2$ h. 


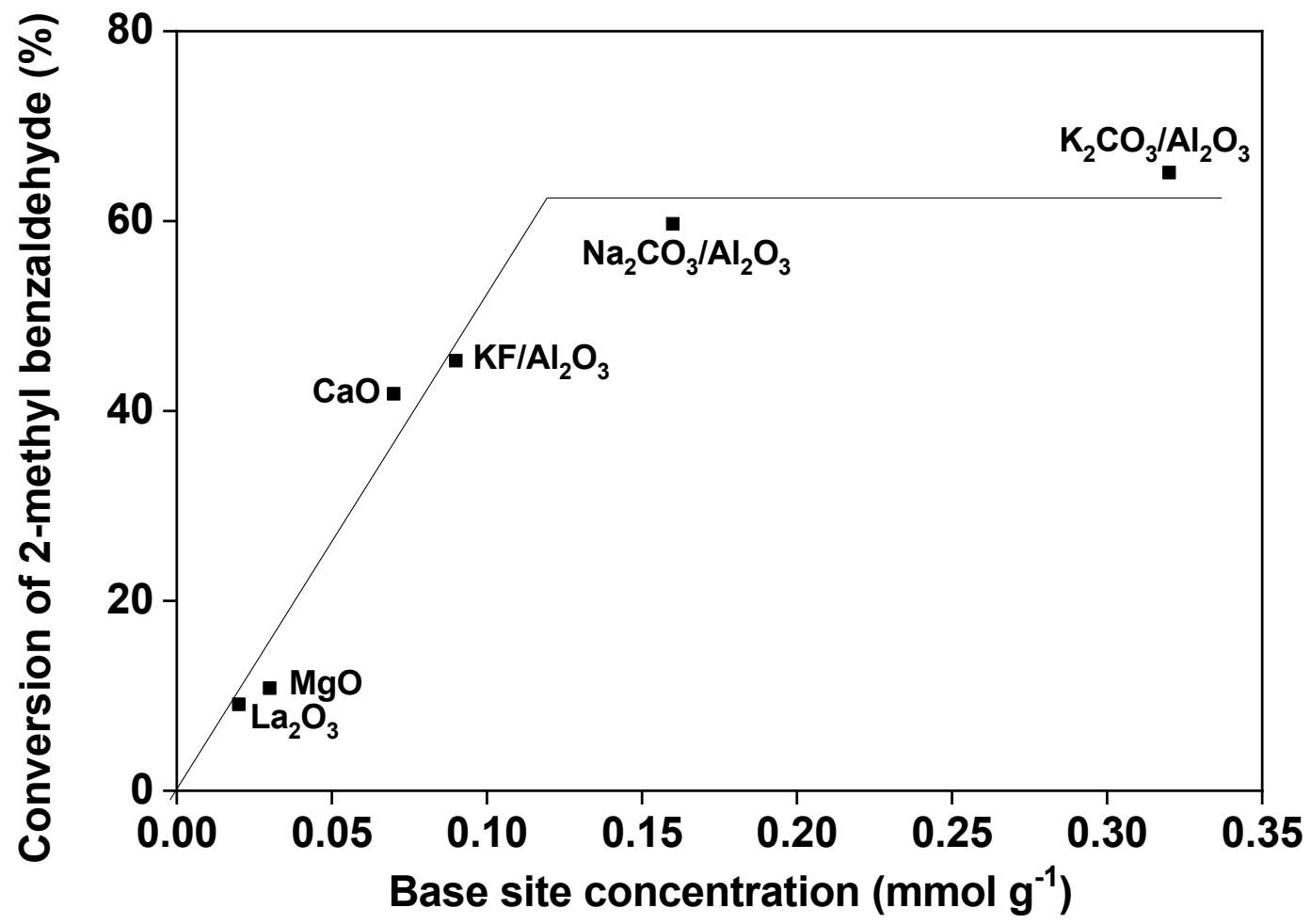

Figure S7. 2-Methyl benzaldehyde conversions and 1A yields over solid bases. Reaction conditions: 10 mmol MIBK, 10 mmol 2-methyl benzaldehyde, 0.2 g catalyst; $393 \mathrm{~K}, 2 \mathrm{~h}$.

To understand the relationship between the base site concentrations on the solid base catalysts and their activities for the aldol condensation of 2-methyl benzaldehyde and MIBK. We investigated the activities of these catalysts at lower reaction temperature and short time. Based on the results illustrate Figure S6, we did a plot of base site concentrations and 2-methyl benzaldehyde conversion. According to Figure S7, 2-methyl benzaldehyde conversion linearly increased with the base site concentration, then stabilized with further increase of base site concentration. Based on this result, we can see that the higher base site concentration is beneficial for the aldol condensation of 2-methyl benzaldehyde and MIBK. 


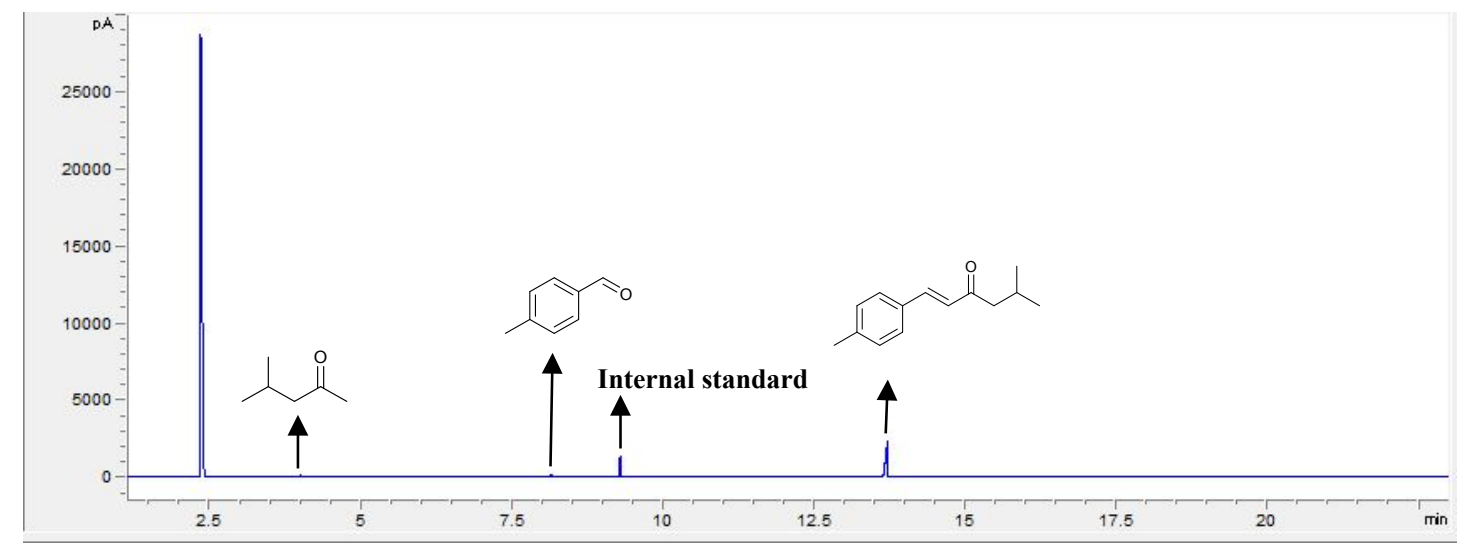

Figure S8. Gas chromatogram of the products from the aldol condensation of 4-methyl benzaldehyde and MIBK. Reaction conditions: $10 \mathrm{mmol} \mathrm{MIBK,} 10 \mathrm{mmol}$ 4-methyl benzaldehyde, $0.2 \mathrm{~g} \mathrm{~K}_{2} \mathrm{CO}_{3} / \mathrm{Al}_{2} \mathrm{O}_{3}$ catalyst; $393 \mathrm{~K}, 6 \mathrm{~h}$. 


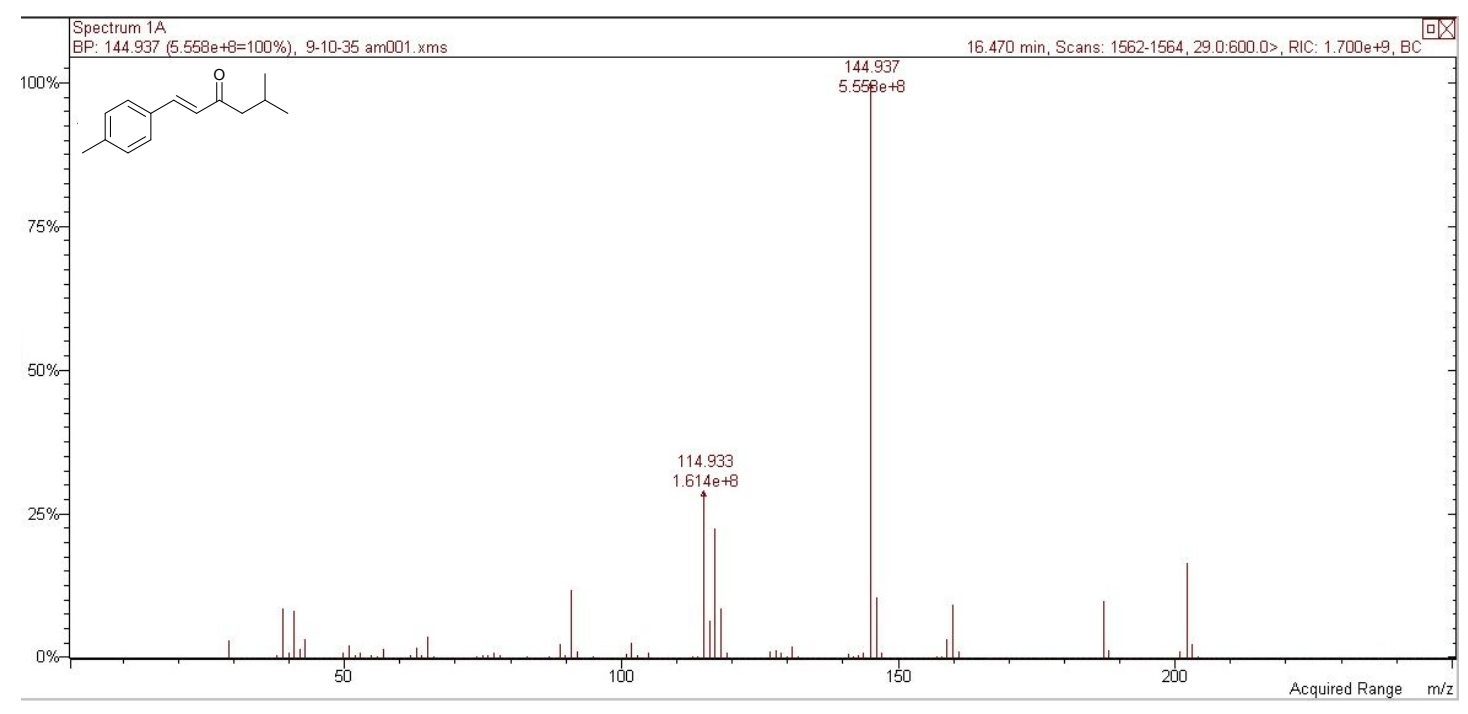

Figure S9. Mass spectrogram of the $\mathbf{2 A}$ from the aldol condensation of 4-methyl benzaldehyde and MIBK. 

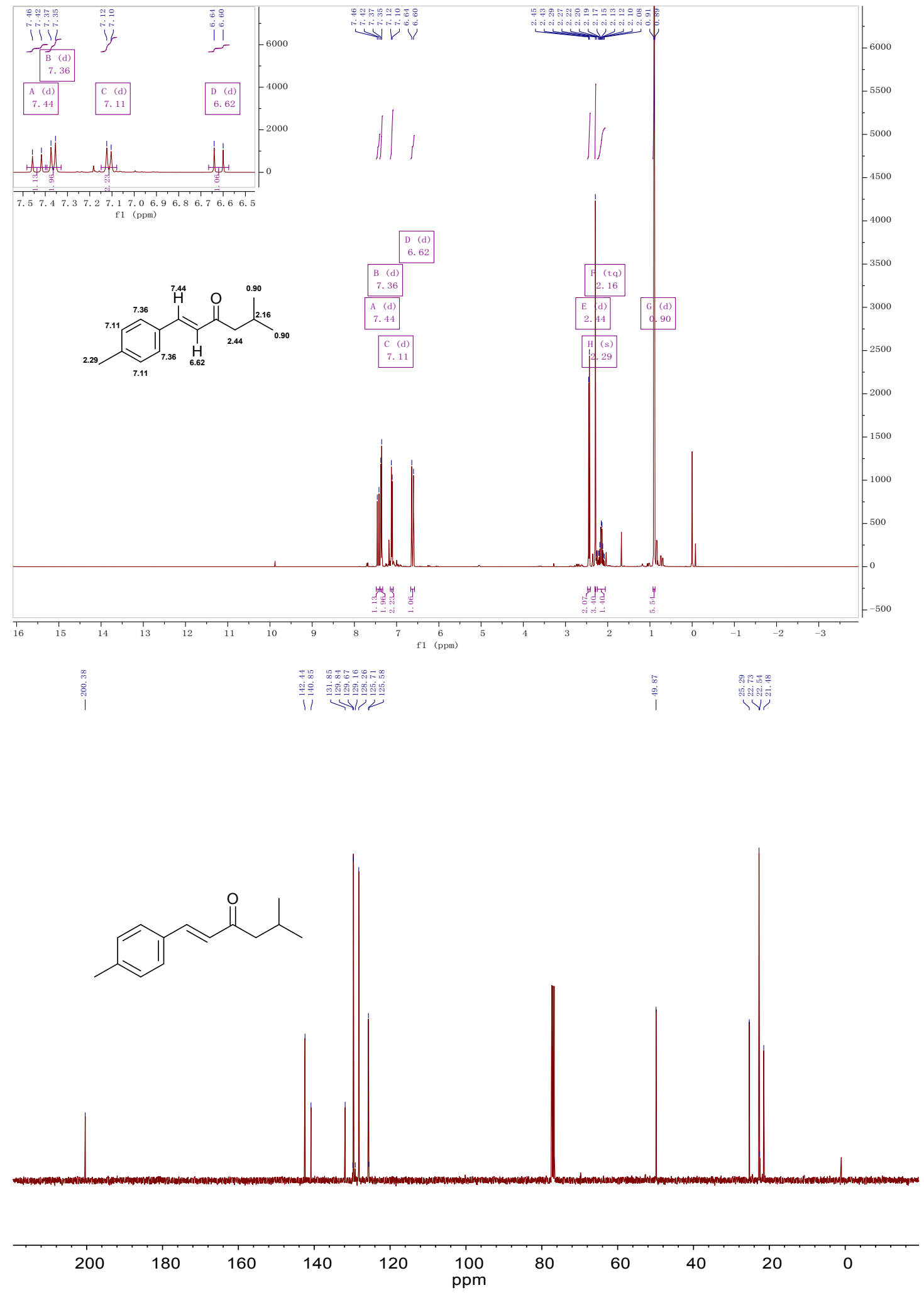

Figure S10. ${ }^{1} \mathrm{H}-\mathrm{NMR}$ and ${ }^{13} \mathrm{C}-\mathrm{NMR}$ spectra of $\mathbf{2 A}$ from the aldol condensation of 4-methyl benzaldehyde and MIBK. 

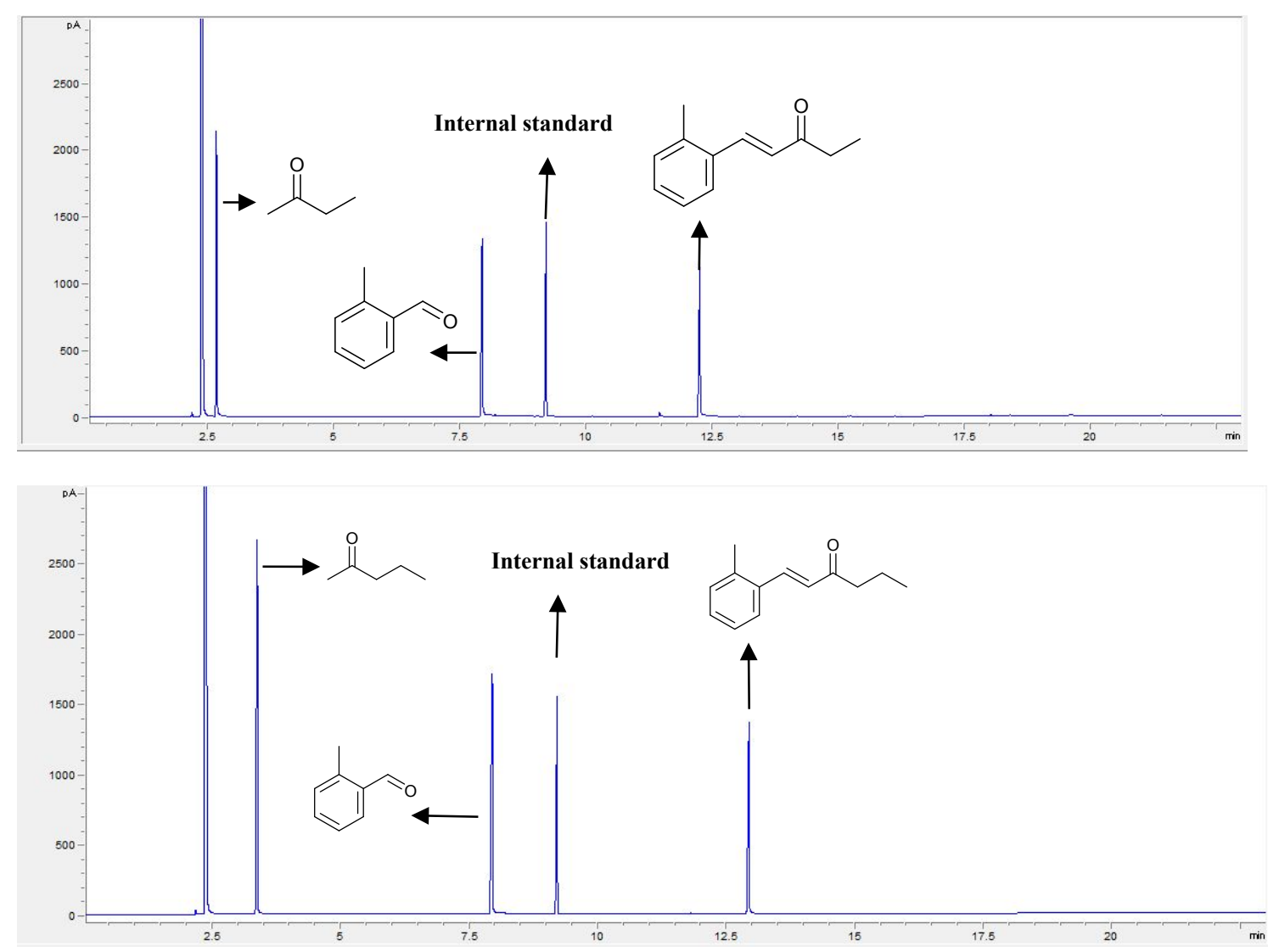

Figure S11. Gas chromatograms of the aldol condensation products of 2-methyl benzaldehyde and butanone (or 2-pentanone). Reaction conditions:20 mmol butanone (or 2-pentanone), $10 \mathrm{mmol}$ 2-methyl benzaldehyde, $0.2 \mathrm{~g} \mathrm{~K}_{2} \mathrm{CO}_{3} / \mathrm{Al}_{2} \mathrm{O}_{3}$ catalyst; $353 \mathrm{~K}, 6 \mathrm{~h}$. 

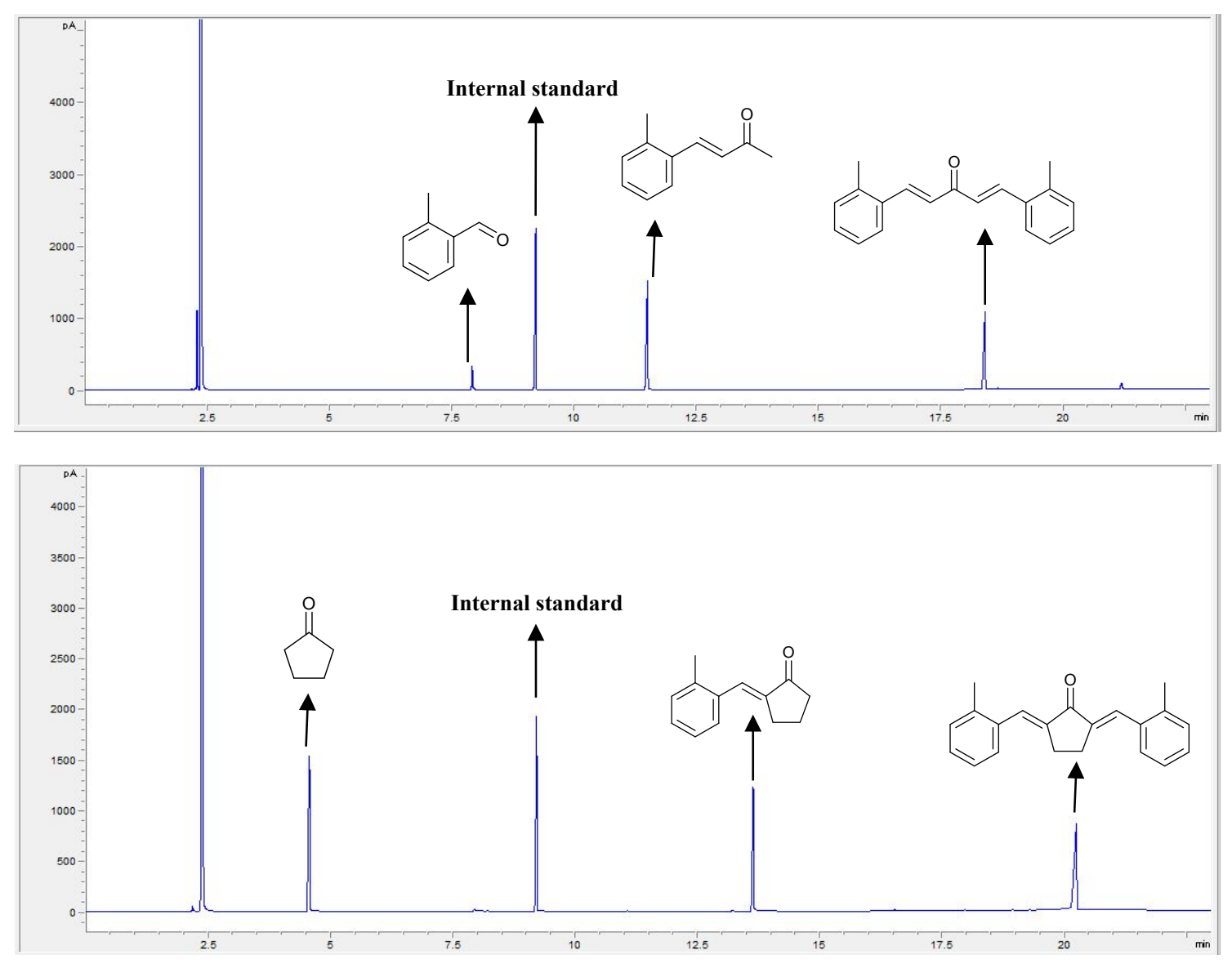

Figure S12. Gas chromatograms of the aldol condensation products of 2-methyl benzaldehyde and acetone (or cyclopentanone). Reaction conditions: $20 \mathrm{mmol}$ acetone (or cyclopentanone), $10 \mathrm{mmol}$ 2-methyl benzaldehyde, $0.2 \mathrm{~g} \mathrm{~K}_{2} \mathrm{CO}_{3} / \mathrm{Al}_{2} \mathrm{O}_{3}$ catalyst; $353 \mathrm{~K}, 6$ h. 


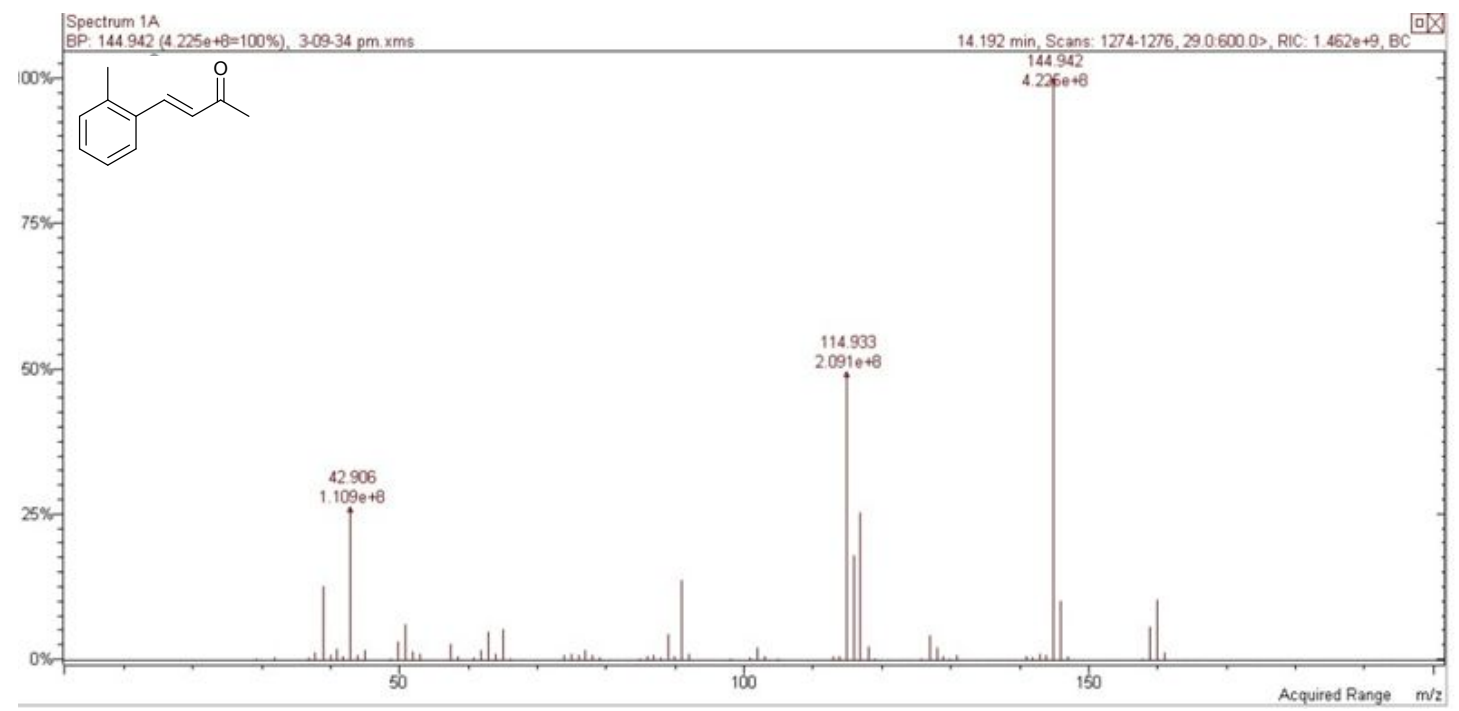

Figure S13. Mass spectrogram of the $\mathbf{3 A}$ from the aldol condensation of 2-methyl benzaldehyde and acetone. 

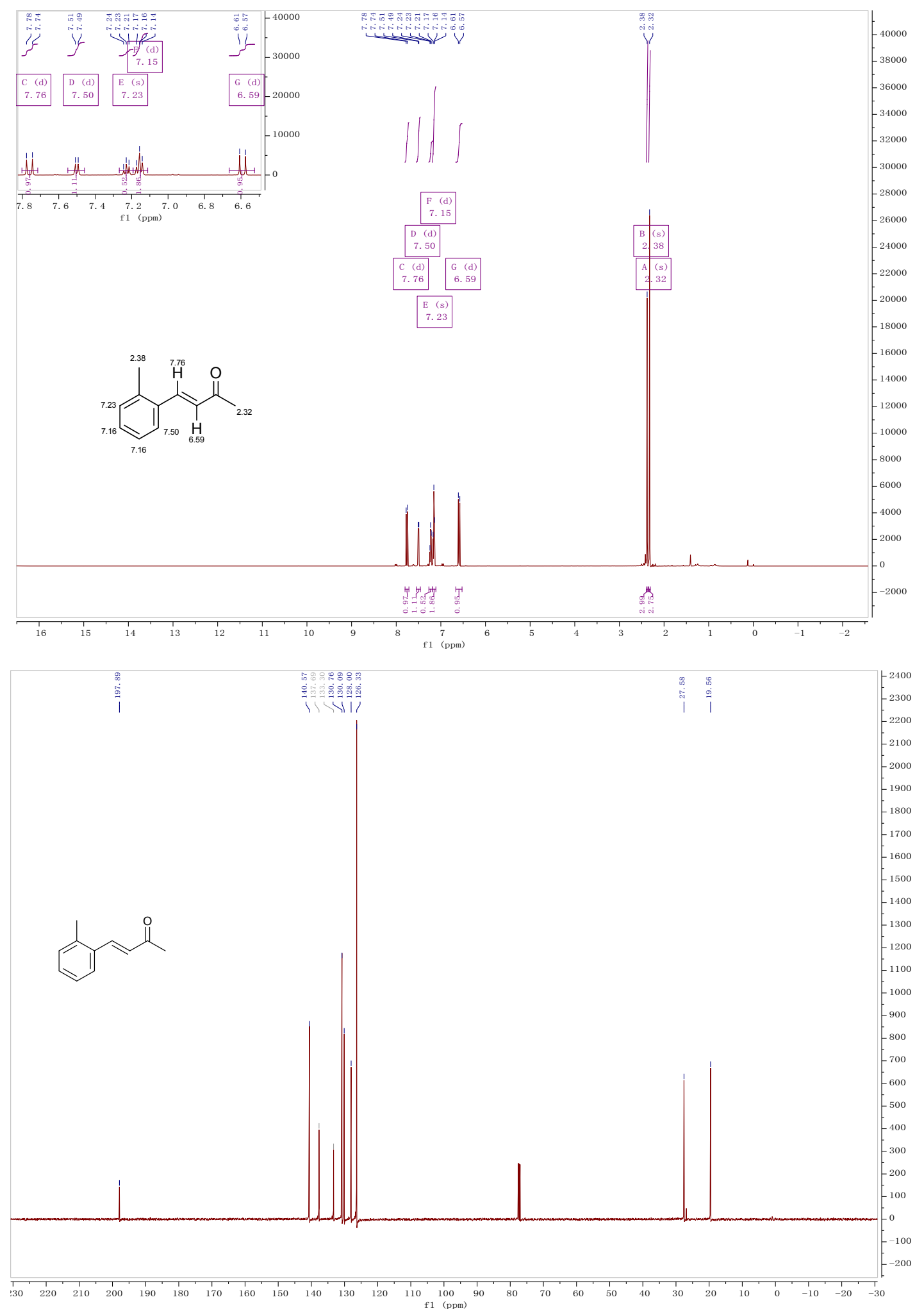

Figure S14. ${ }^{1} \mathrm{H}-\mathrm{NMR}$ and ${ }^{13} \mathrm{C}-\mathrm{NMR}$ spectra of $\mathbf{3 A}$ from the aldol condensation of 2-methyl benzaldehyde and acetone. 


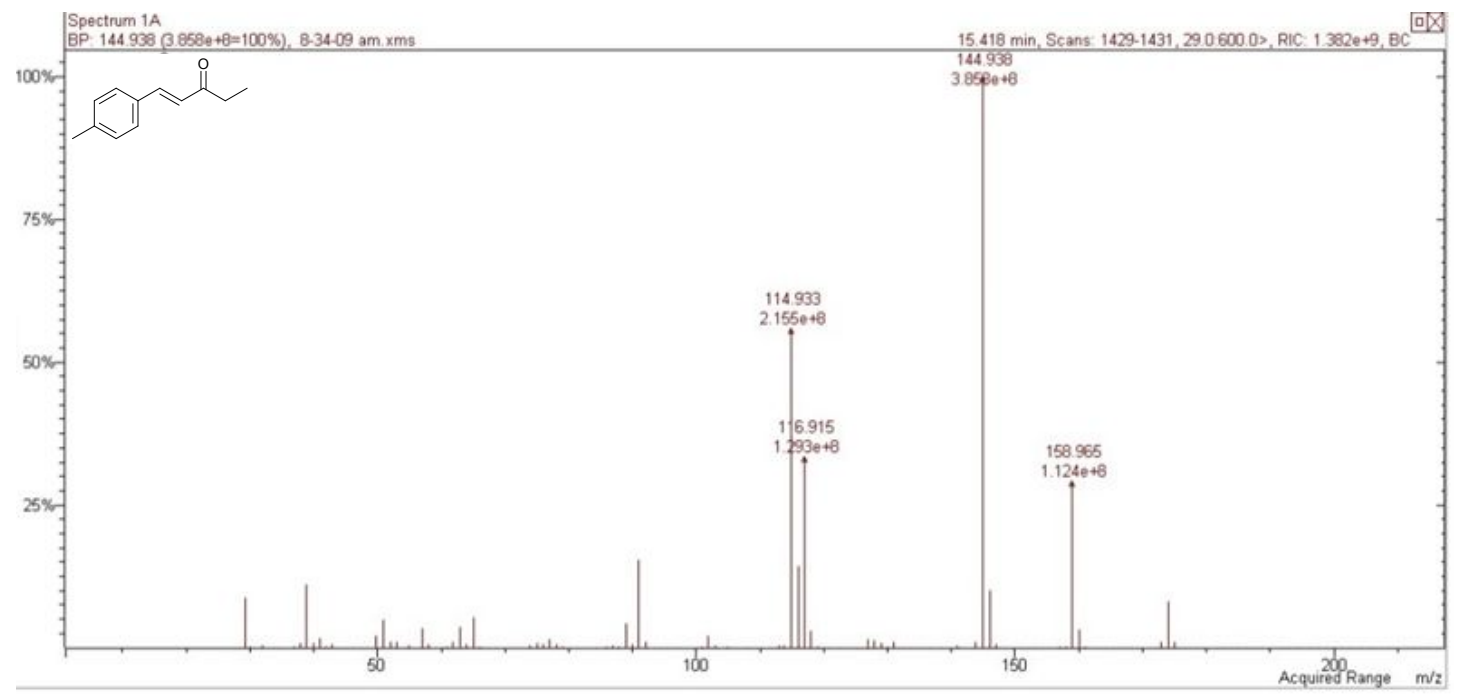

Figure S15. Mass spectrogram of the $\mathbf{4 A}$ from the aldol condensation of 2-methyl benzaldehyde and 2-butanone. 

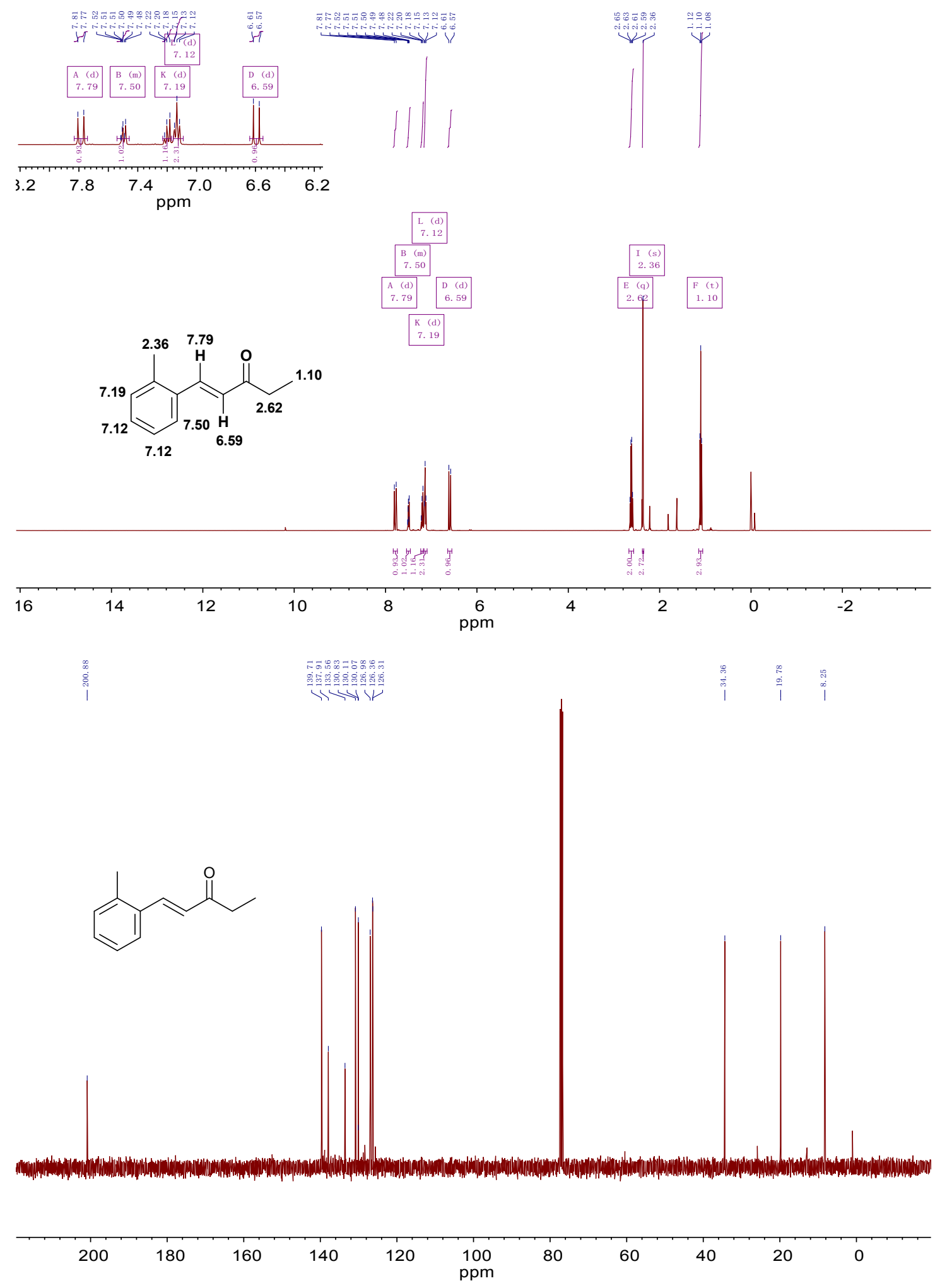

Figure S16. ${ }^{1} \mathrm{H}-\mathrm{NMR}$ and ${ }^{13} \mathrm{C}-\mathrm{NMR}$ spectra of the $\mathbf{4 A}$ from the aldol condensation of

2-methyl benzaldehyde and 2-butanone. 


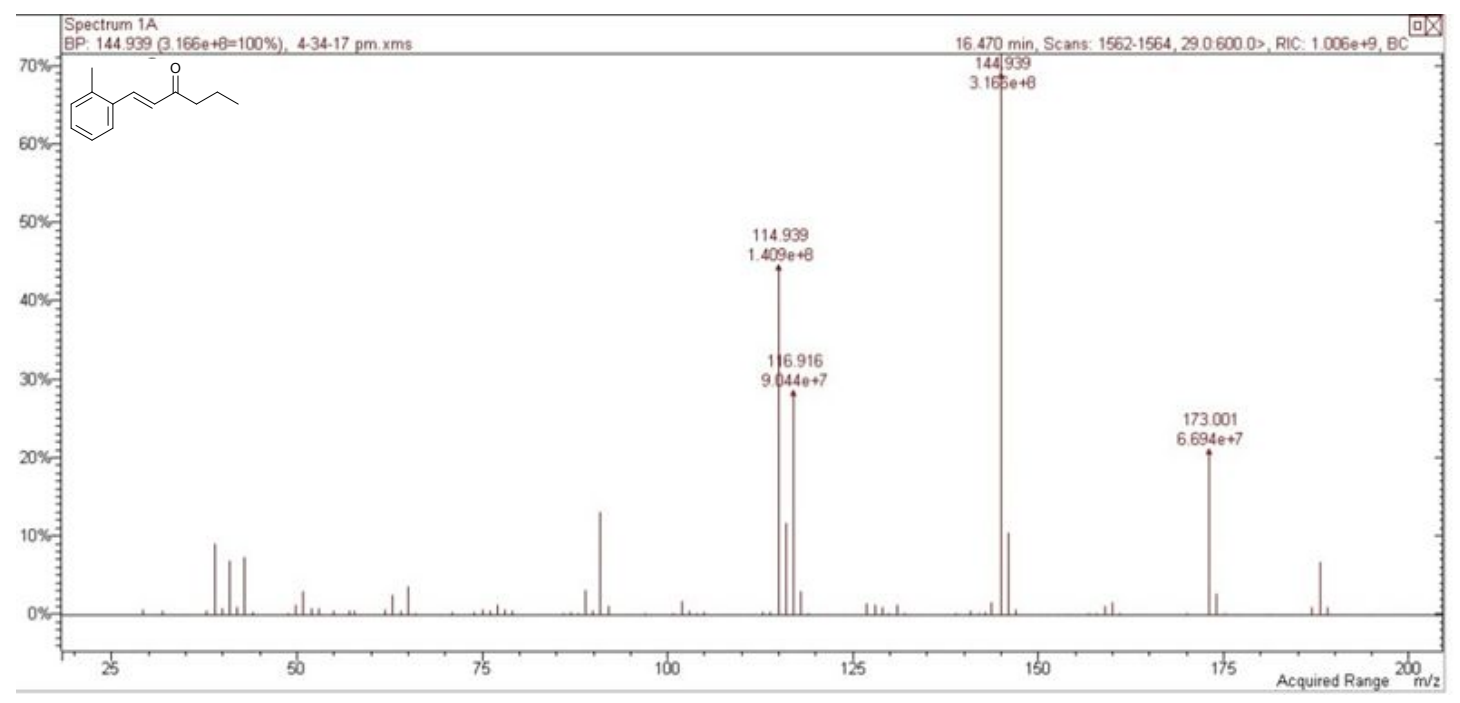

Figure S17. Mass spectrogram of the $\mathbf{5 A}$ from the aldol condensation of 2-methyl benzaldehyde and 2-pentanone. 

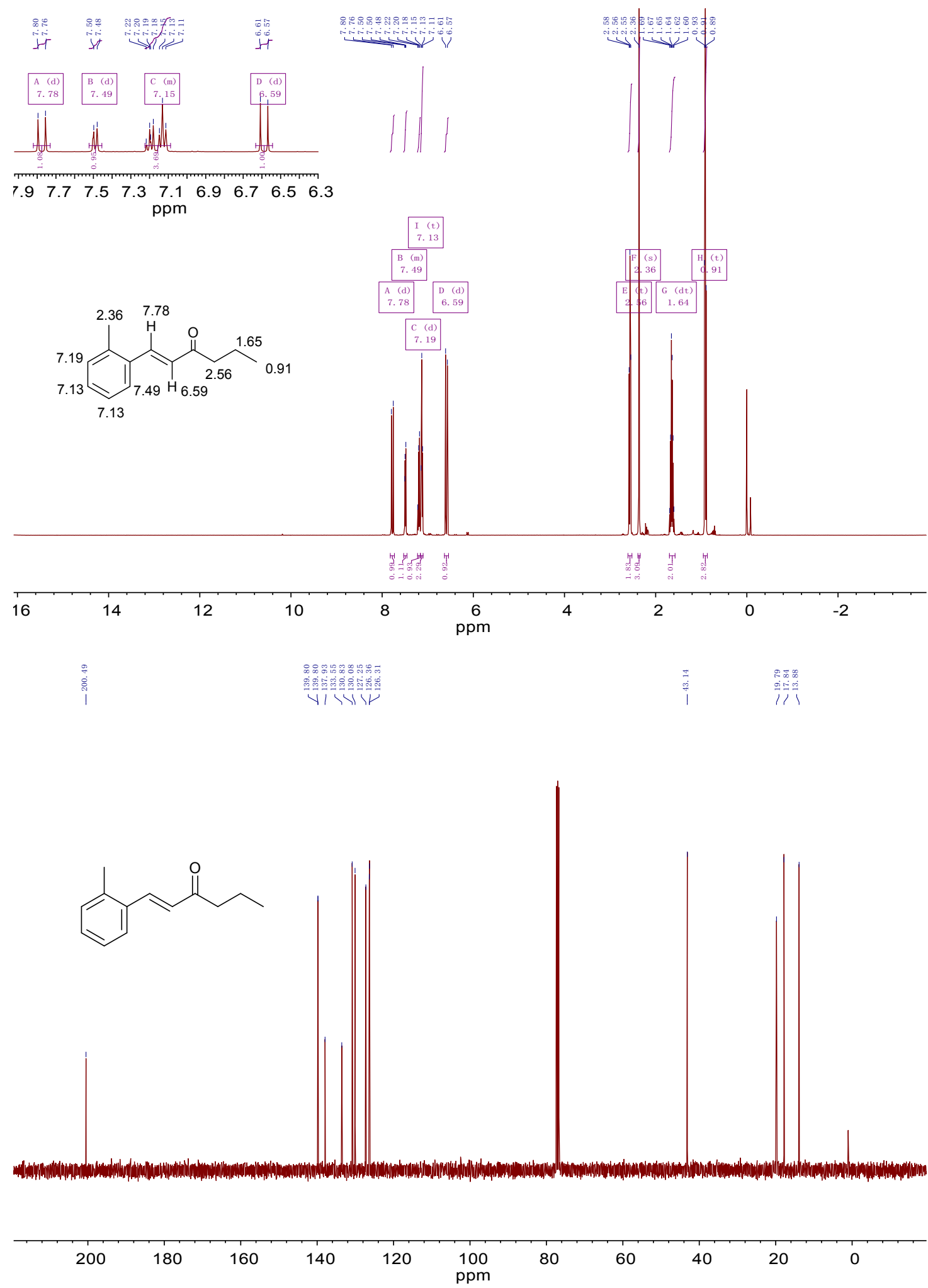

Figure S18. ${ }^{1} \mathrm{H}-\mathrm{NMR}$ and ${ }^{13} \mathrm{C}-\mathrm{NMR}$ spectra of $\mathbf{5 A}$ from the aldol condensation of

2-methyl benzaldehyde and 2-pentanone. 


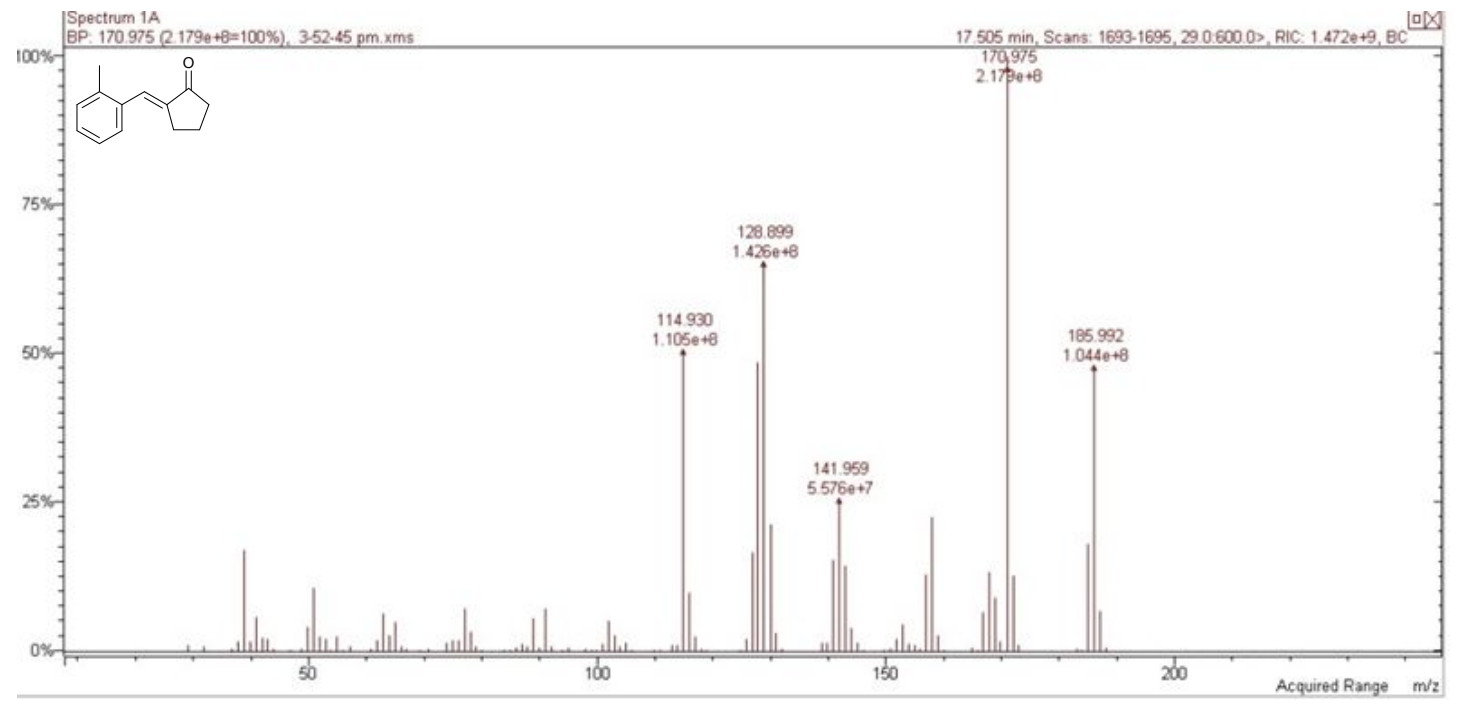

Figure S19. Mass spectrogram of the 6A from the aldol condensation of 2-methyl benzaldehyde and cyclopentanone. 

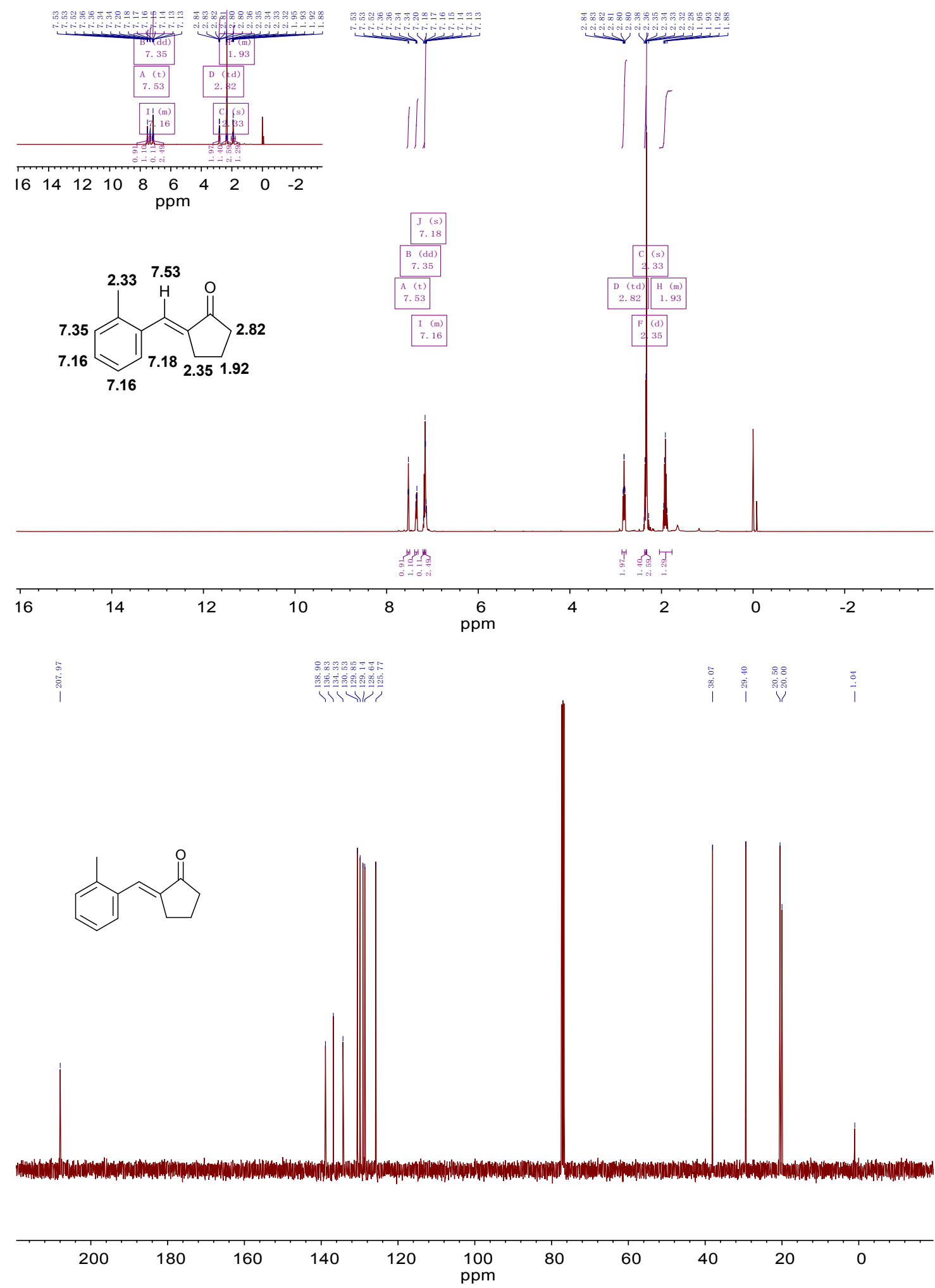

Figure S20. ${ }^{1} \mathrm{H}-\mathrm{NMR}$ and ${ }^{13} \mathrm{C}-\mathrm{NMR}$ spectra of $\mathbf{6 A}$ from the aldol condensation of 2-methyl benzaldehyde and cyclopentanone. 


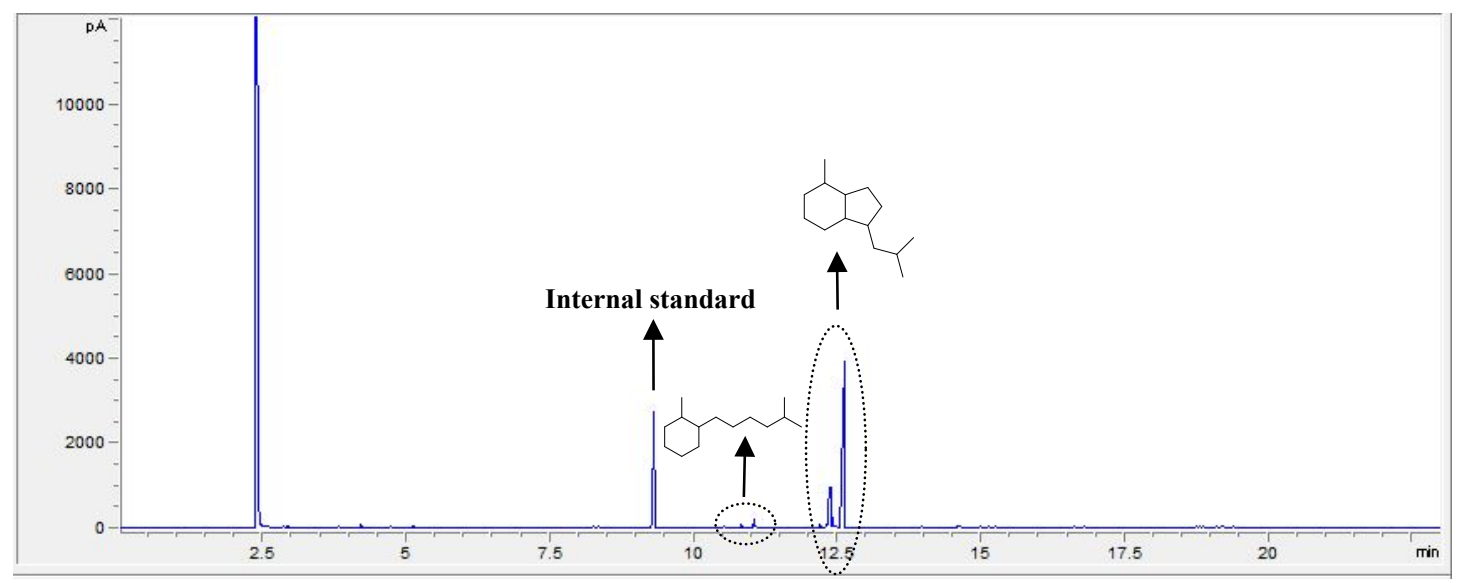

Figure S21. Gas chromatogram of the aqueous phase hydrodeoxygenation (HDO) product of 1A. Reaction conditions: $10 \mathrm{mmol} \mathbf{1 A}, 0.1 \mathrm{~g} \mathrm{Pt} / \mathrm{C}$ catalyst, $50 \mathrm{~mL} \mathrm{H}_{2} \mathrm{O}$; $453 \mathrm{~K}, 6 \mathrm{MPa} \mathrm{H}_{2}, 1 \mathrm{~h}$. 


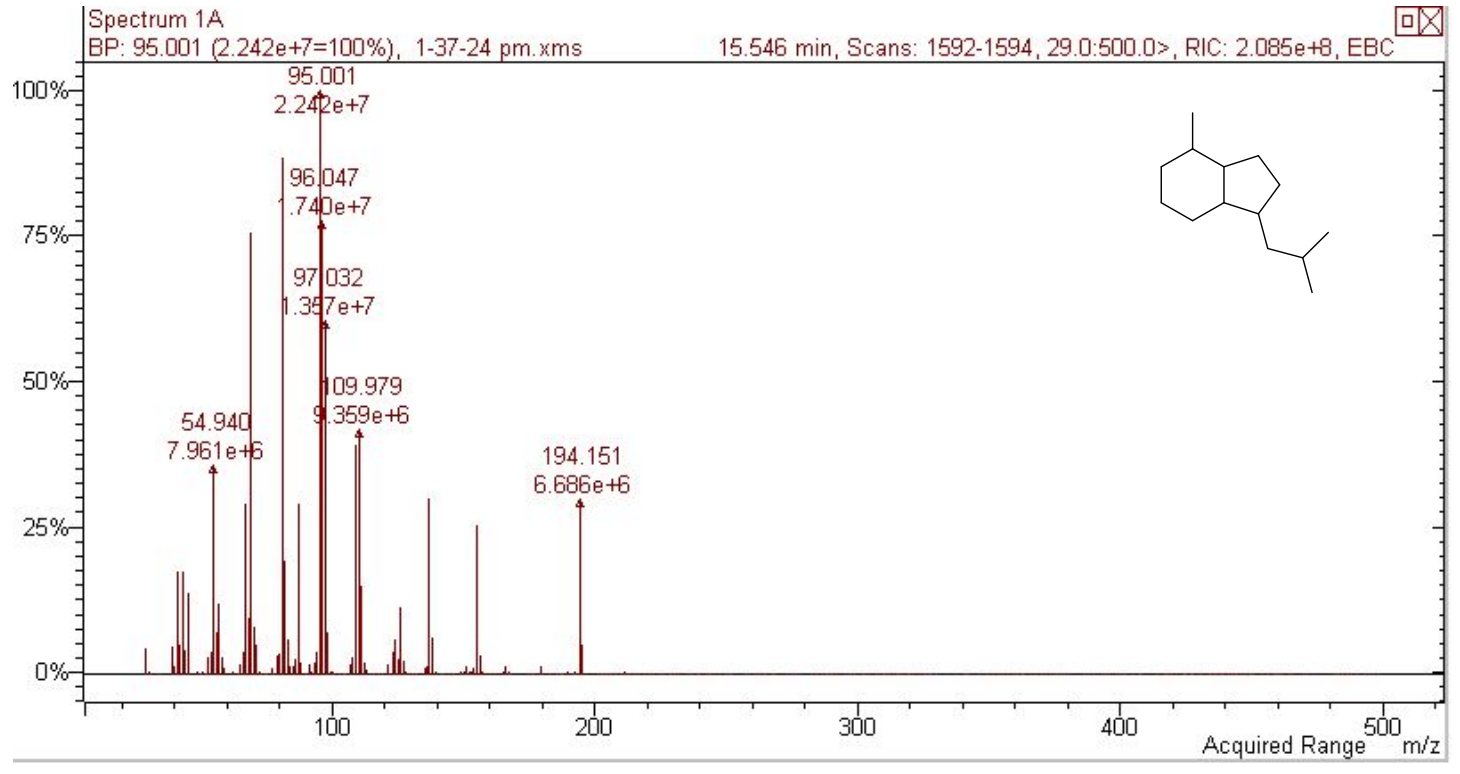

Figure S22. Mass spectrogram of 1B from the aqueous phase HDO of 1A. 


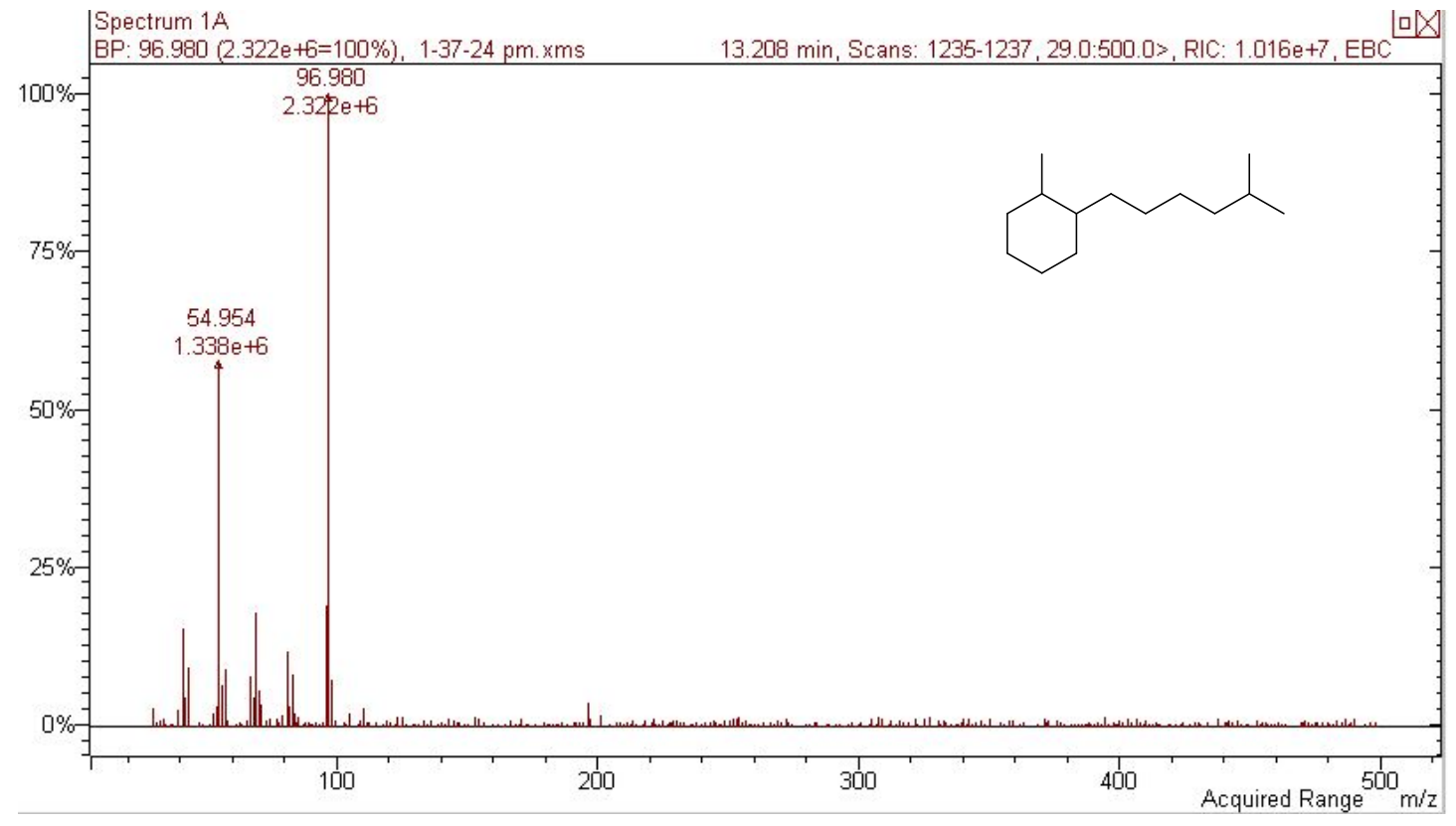

Figure S23. Mass spectrogram of $\mathbf{1 C}$ from the aqueous phase HDO of $\mathbf{1 A}$. 


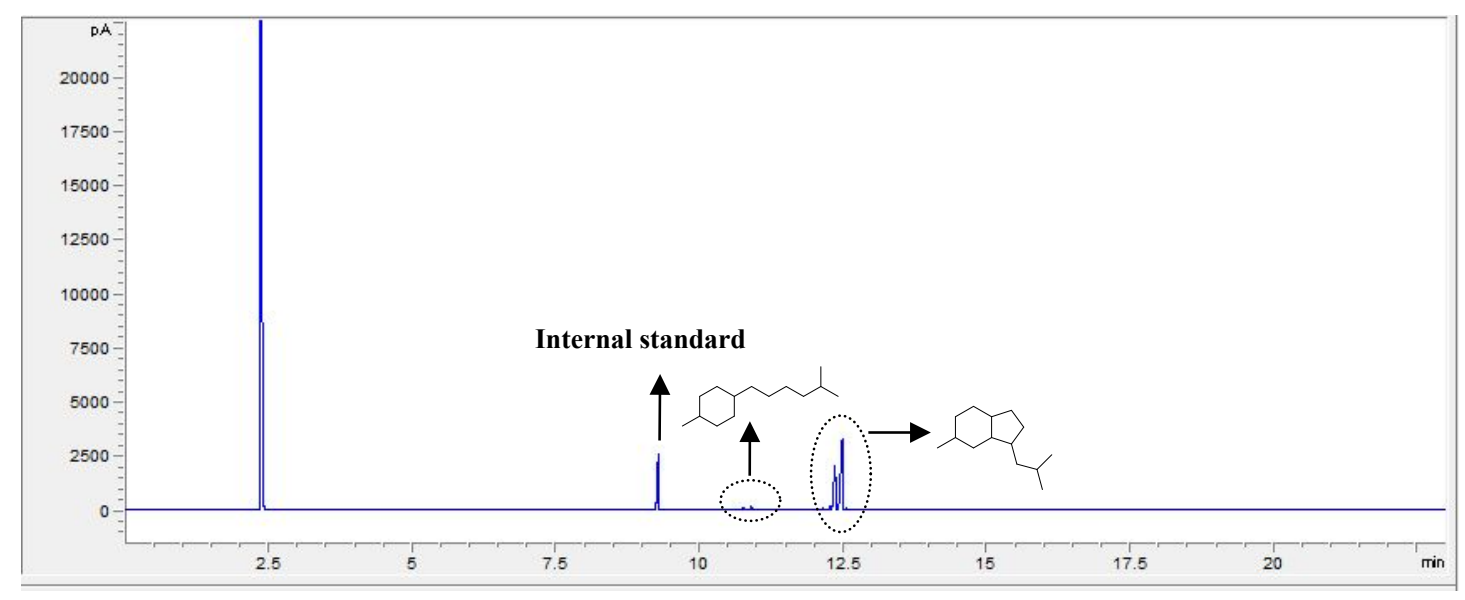

Figure S24. Gas chromatogram of the aqueous phase HDO product of $\mathbf{2 A}$. Reaction conditions: 10 mmol 2A, $0.1 \mathrm{~g} \mathrm{Pt} / \mathrm{C}$ catalyst, $50 \mathrm{~mL} \mathrm{H} \mathrm{H}_{2} \mathrm{O} ; 453 \mathrm{~K}, 6 \mathrm{MPa} \mathrm{H}_{2}, 1 \mathrm{~h}$. 


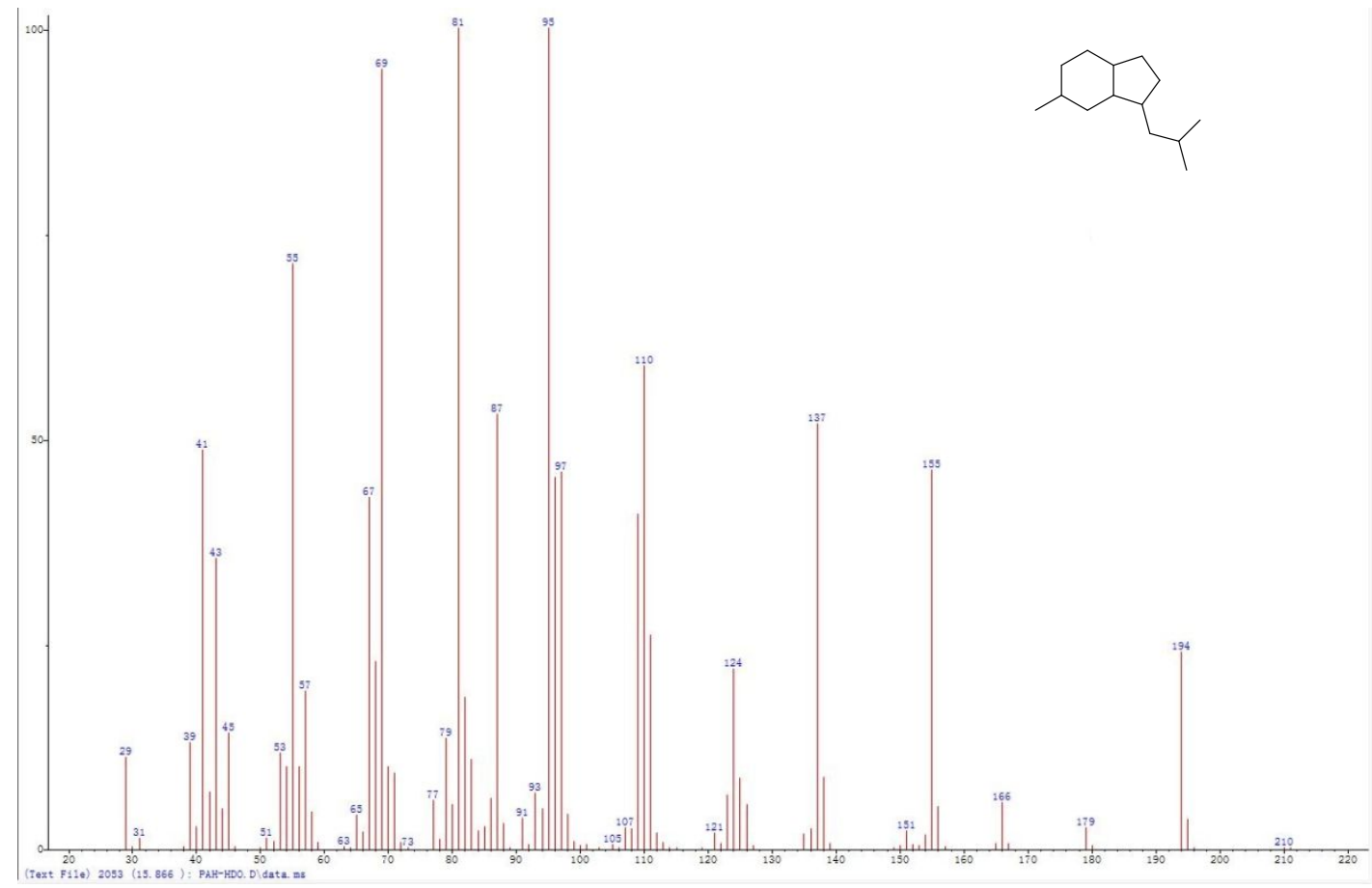

Figure S25. Mass spectrogram of 2B from the aqueous phase HDO of $\mathbf{2 A}$. 


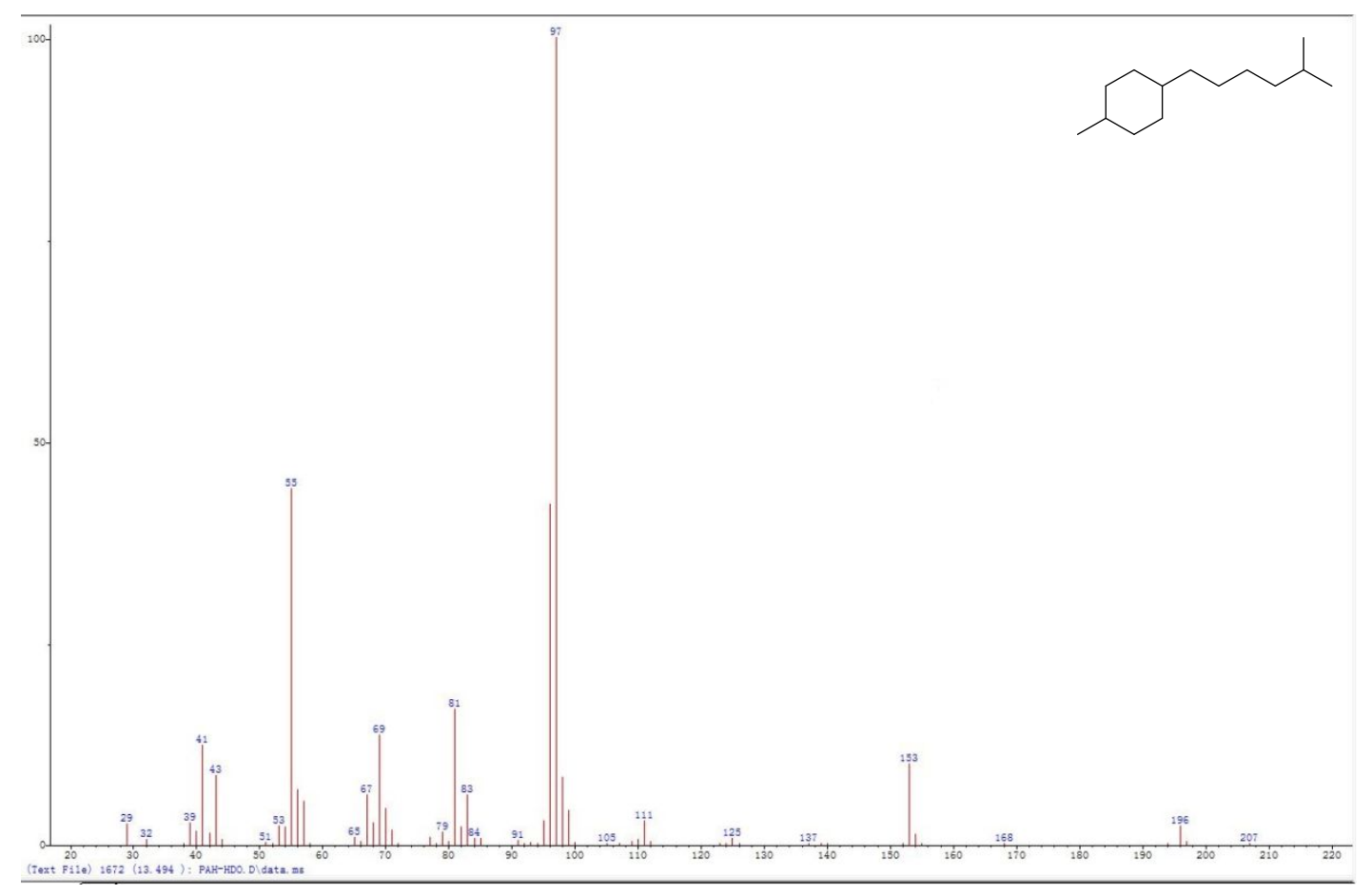

Figure S26. Mass spectrogram of $\mathbf{2 C}$ from the aqueous phase HDO of $\mathbf{2 A}$. 


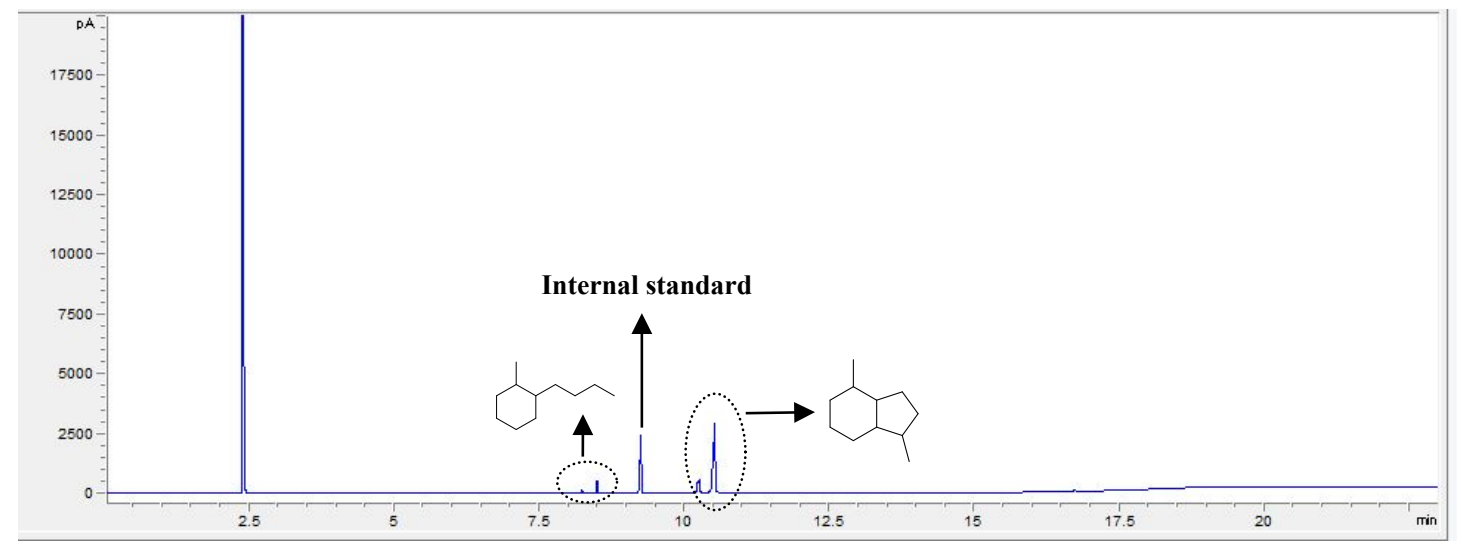

Figure S27. Gas chromatogram of the aqueous phase HDO product of $\mathbf{3 A}$. Reaction conditions: 10 mmol 3A, $0.1 \mathrm{~g} \mathrm{Pt} / \mathrm{C}$ catalyst, $50 \mathrm{~mL} \mathrm{H}_{2} \mathrm{O}$; $453 \mathrm{~K}, 6 \mathrm{MPa} \mathrm{H}_{2}, 1 \mathrm{~h}$. 


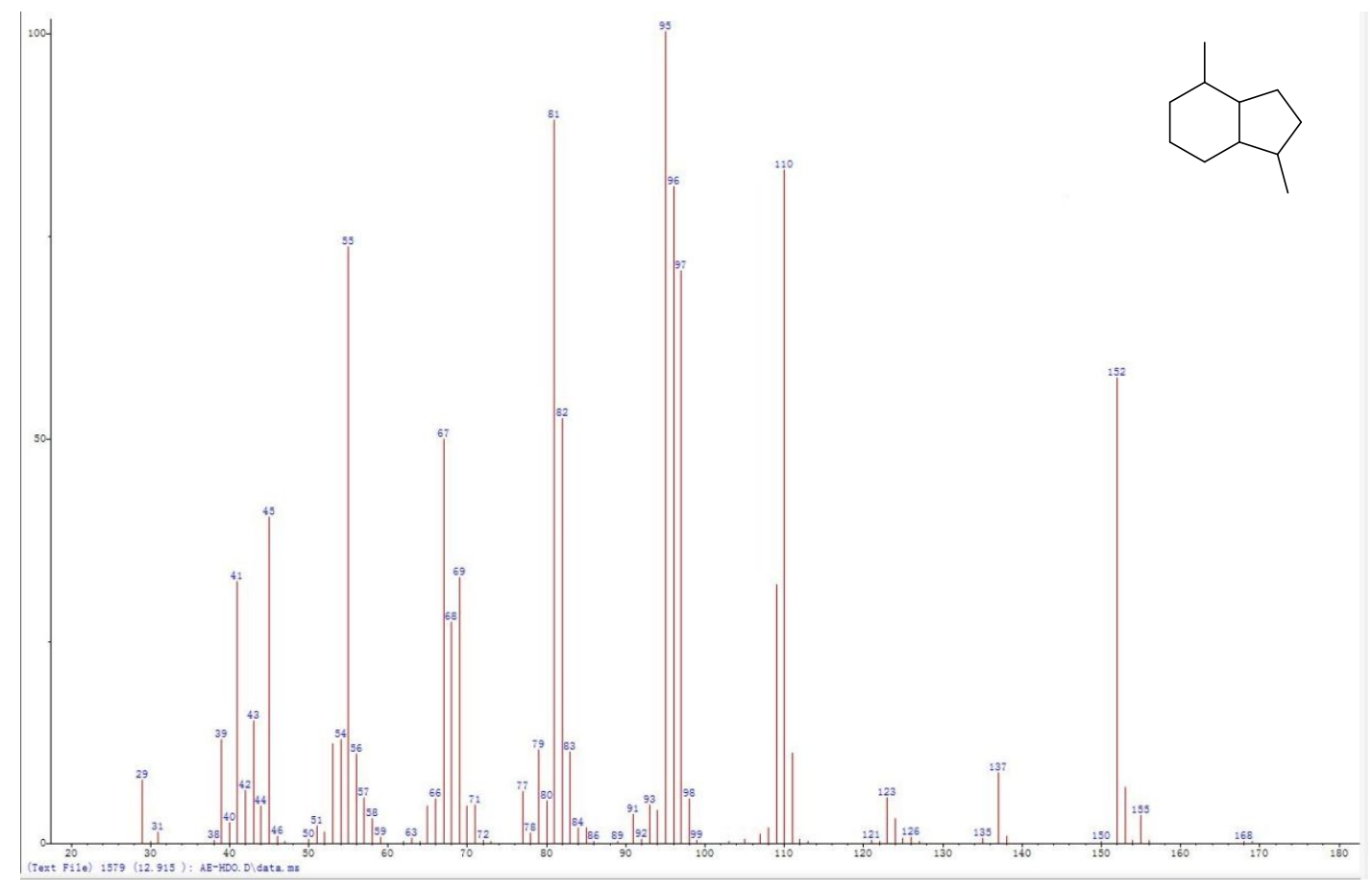

Figure S28. Mass spectrogram of $\mathbf{3 B}$ from the aqueous phase HDO of $\mathbf{3 A}$. 


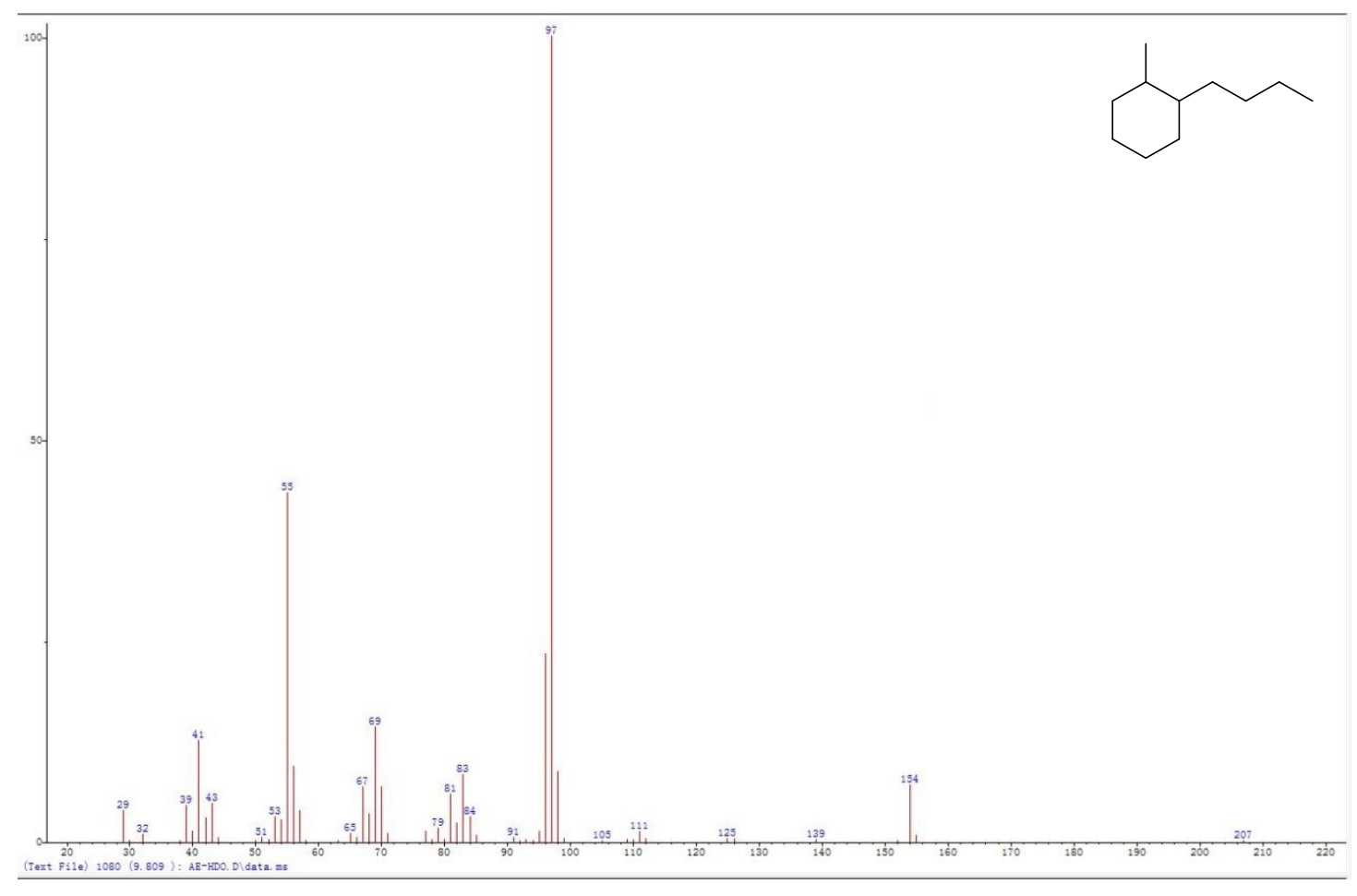

Figure S29. Mass spectrogram of $\mathbf{3 C}$ from the aqueous phase HDO of $\mathbf{3 A}$. 


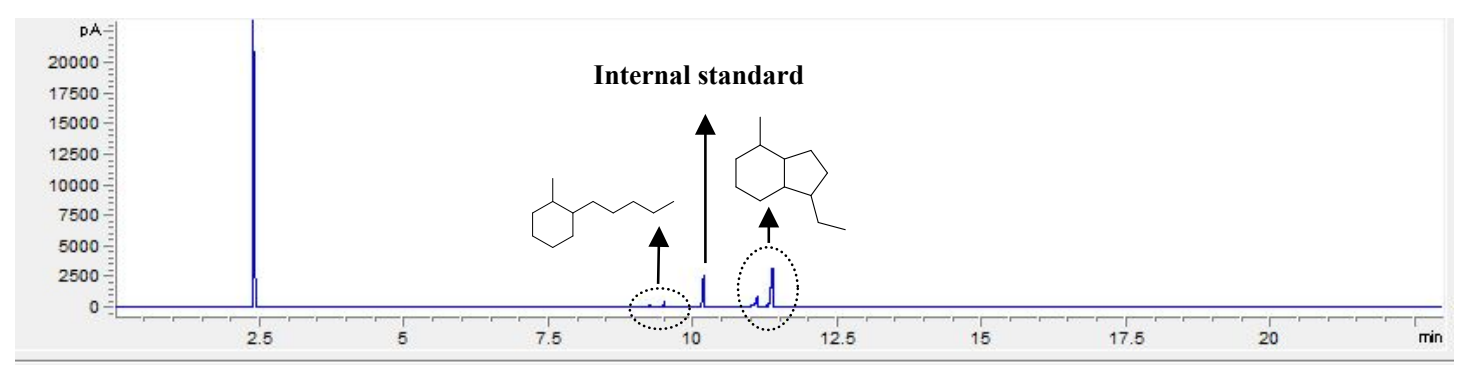

Figure S30. Gas chromatogram of the aqueous phase HDO product of 4A. Reaction conditions: $10 \mathrm{mmol} \mathrm{4A}, 0.1 \mathrm{~g} \mathrm{Pt} / \mathrm{C}$ catalyst, $50 \mathrm{~mL} \mathrm{H} \mathrm{H}_{2} \mathrm{O} ; 453 \mathrm{~K}, 6 \mathrm{MPa} \mathrm{H}_{2}, 1 \mathrm{~h}$. 


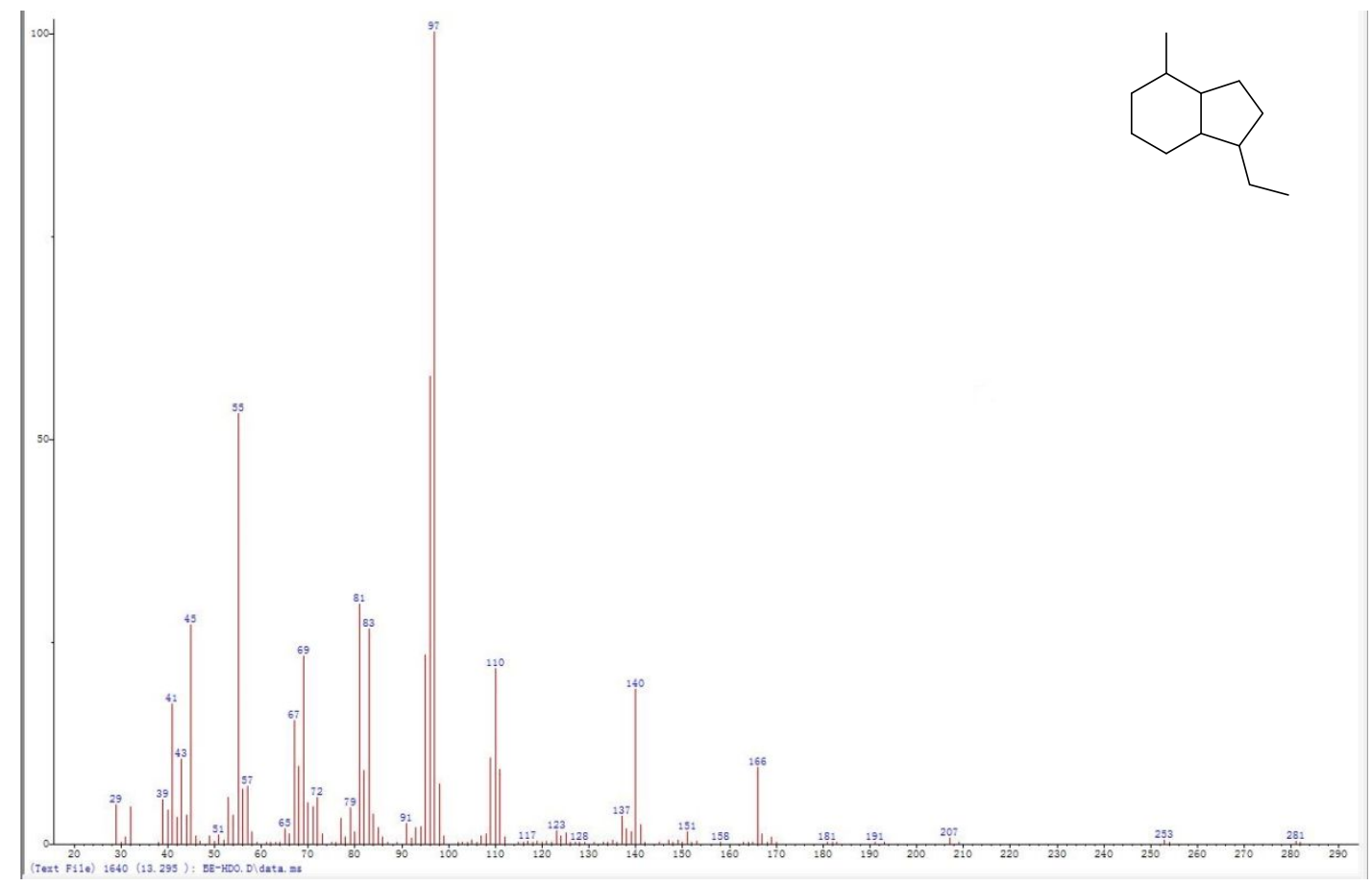

Figure S31. Mass spectrogram of the 4B from the aqueous phase HDO of 4A. 


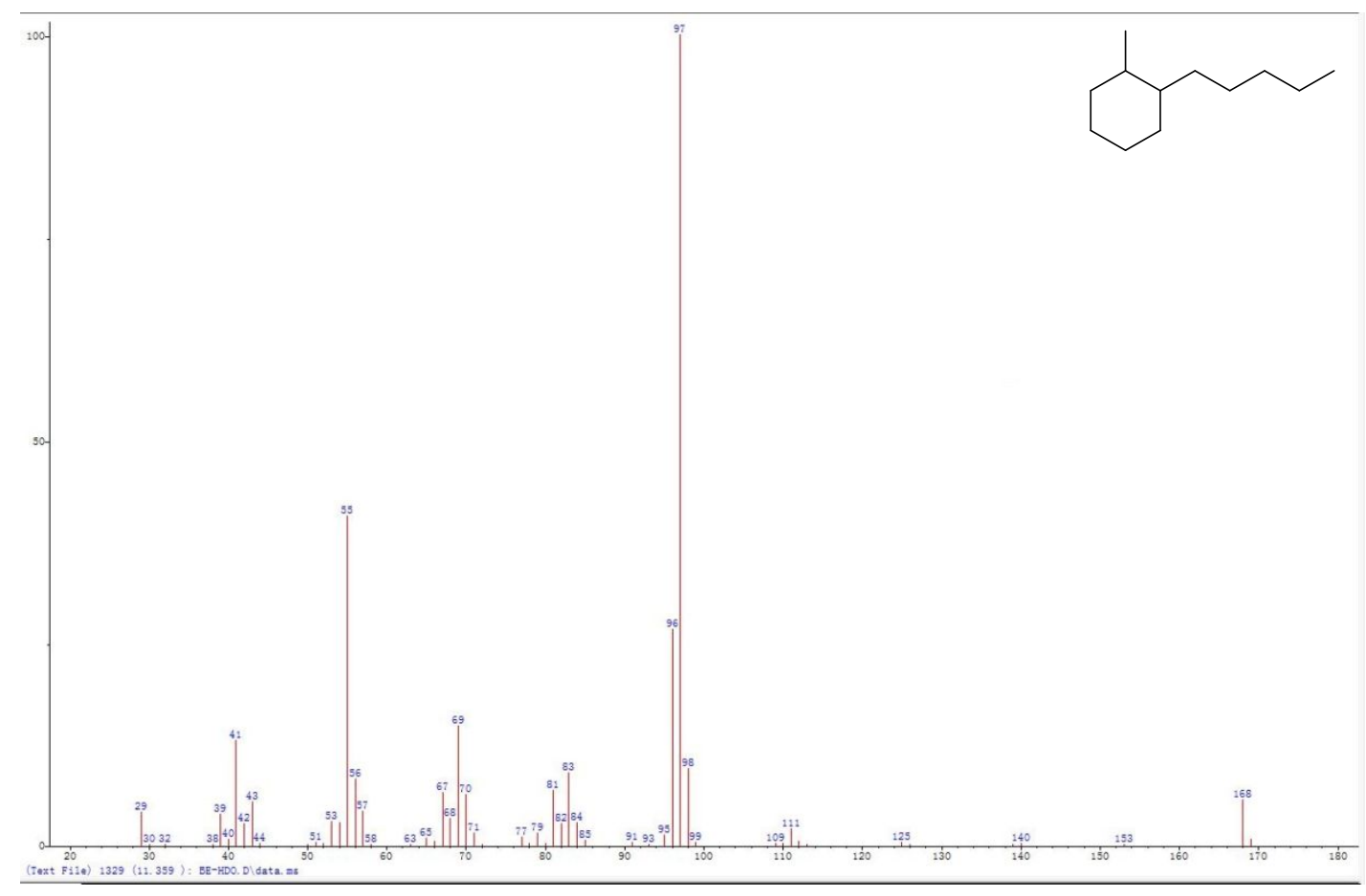

Figure S32. Mass spectrogram of the $\mathbf{4 C}$ from the aqueous phase HDO of $4 \mathrm{~A}$. 


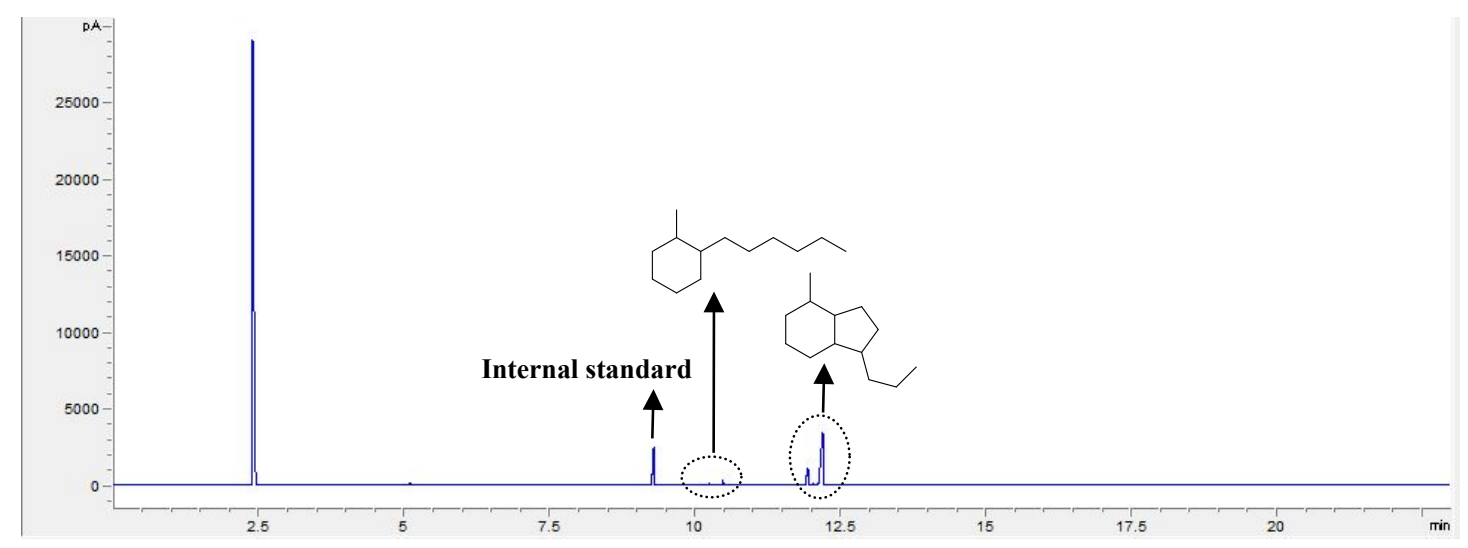

Figure S33. Gas chromatogram of the aqueous phase HDO product of 5A. Reaction conditions: $10 \mathrm{mmol}$ 5A, $0.1 \mathrm{~g} \mathrm{Pt} / \mathrm{C}$ catalyst, $50 \mathrm{~mL} \mathrm{H}{ }_{2} \mathrm{O} ; 453 \mathrm{~K}, 6 \mathrm{MPa} \mathrm{H}{ }_{2}, 1 \mathrm{~h}$. 


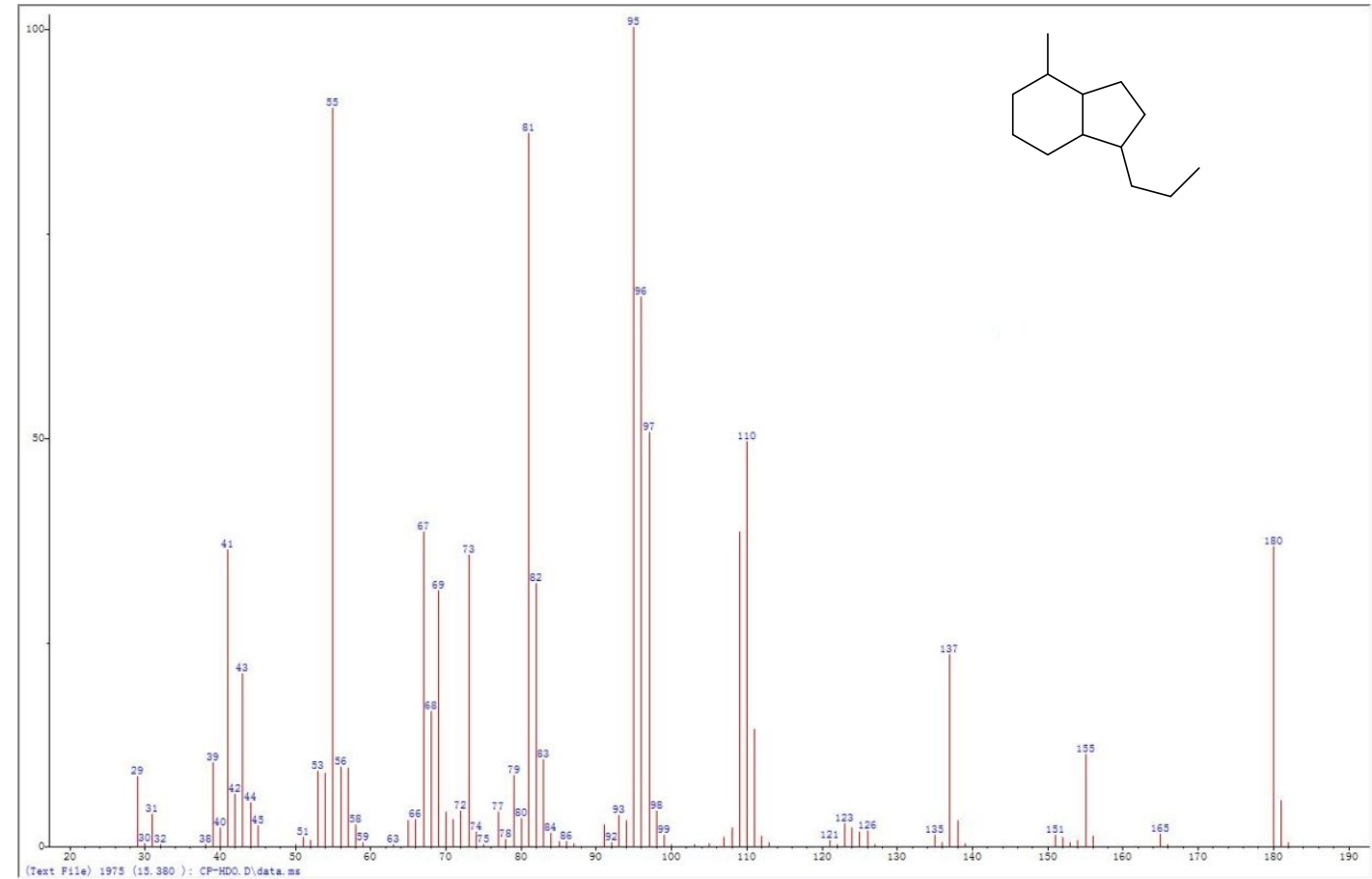

Figure S34. Mass spectrogram of the 5B from the aqueous phase HDO of $\mathbf{5 A}$. 


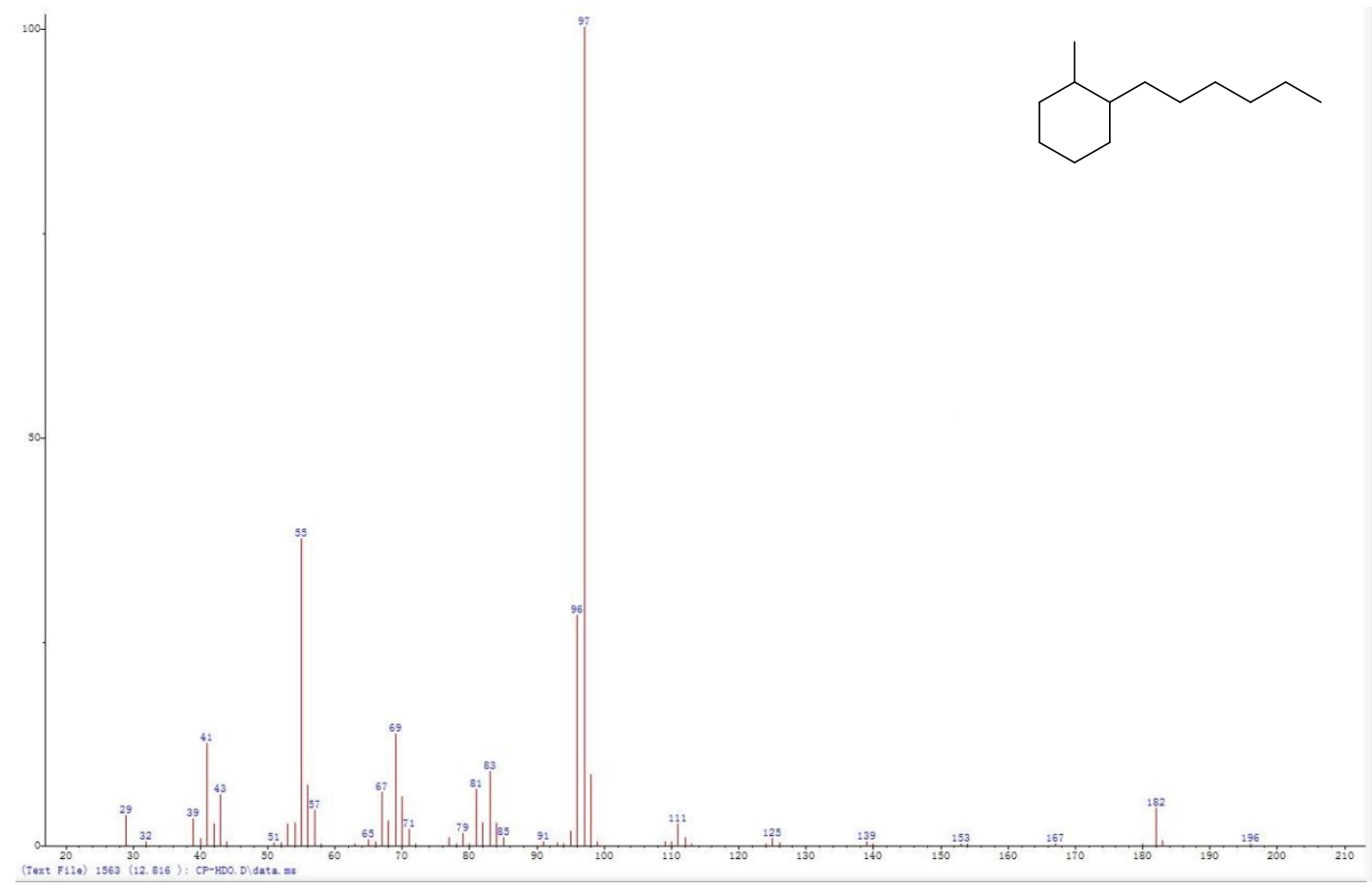

Figure S35. Mass spectrogram of the $\mathbf{5 C}$ from the aqueous phase HDO of $\mathbf{5 A}$. 


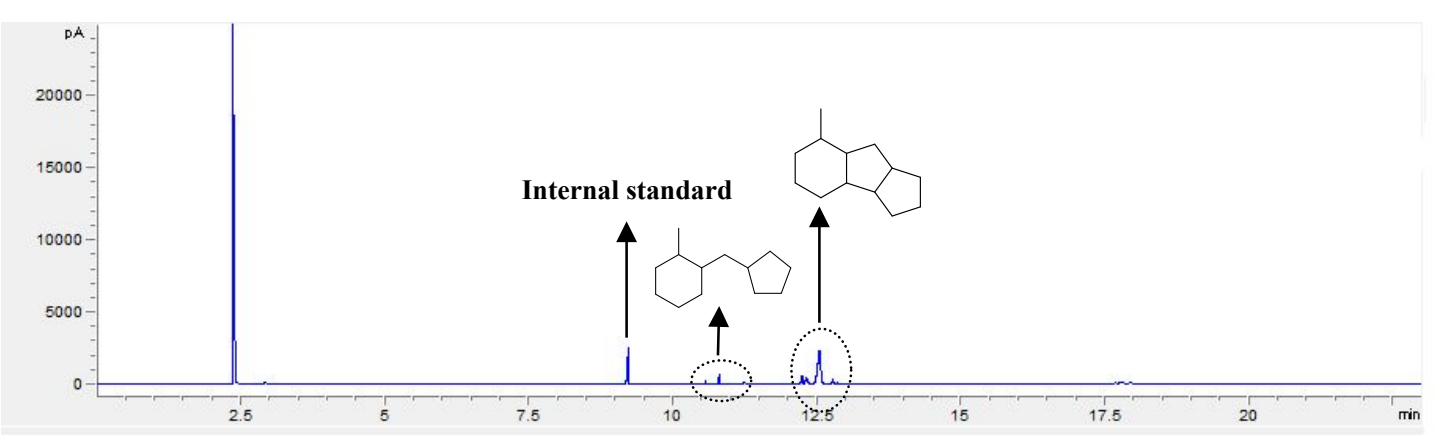

Figure S36. Gas chromatogram of the aqueous phase HDO product of 6A. Reaction conditions: $10 \mathrm{mmol} \mathrm{6A}, 0.1 \mathrm{~g} \mathrm{Pt} / \mathrm{C}$ catalyst, $50 \mathrm{~mL} \mathrm{H} \mathrm{H}_{2} \mathrm{O} ; 453 \mathrm{~K}, 6 \mathrm{MPa} \mathrm{H}_{2}, 1 \mathrm{~h}$. 


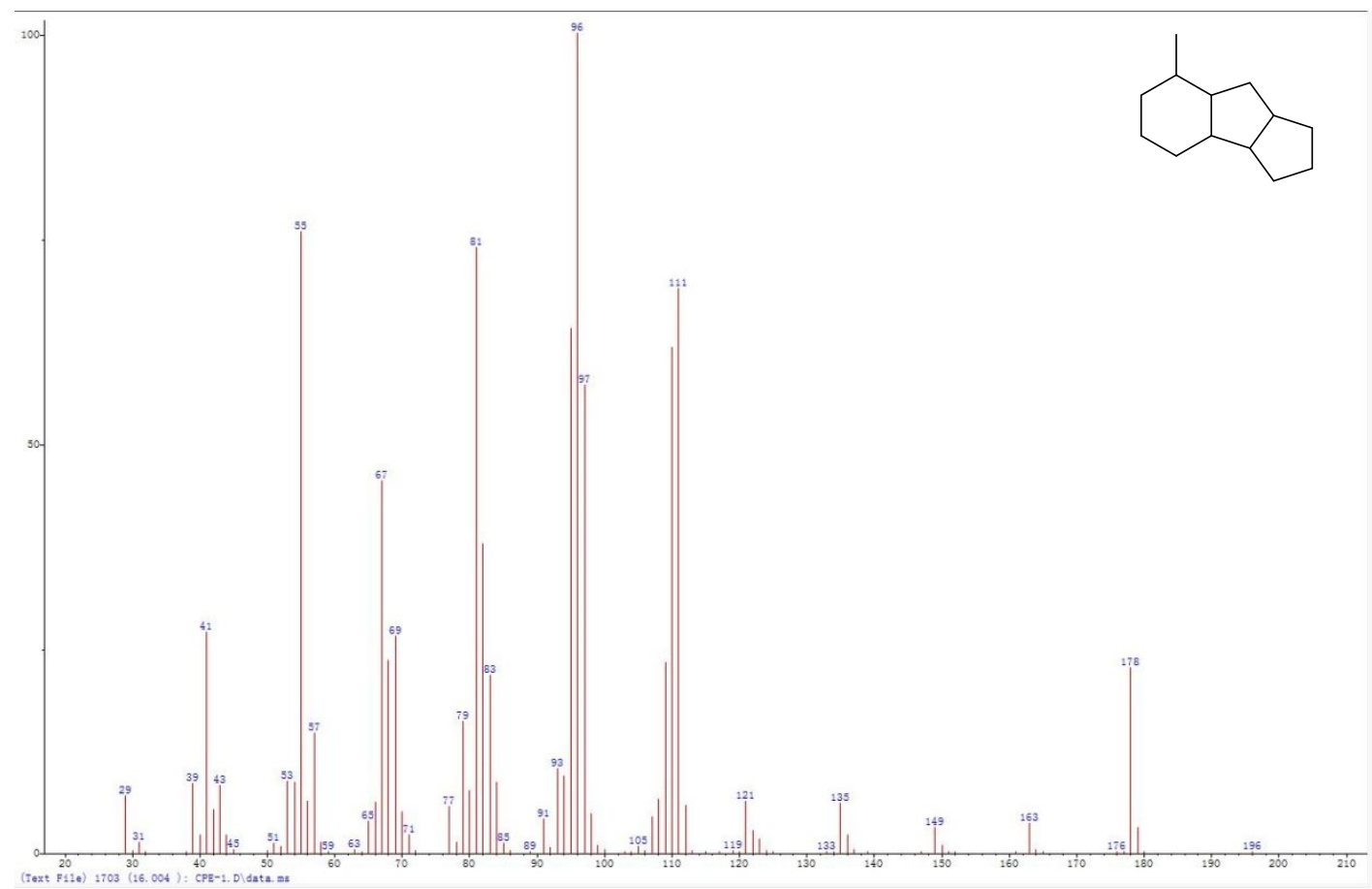

Figure S37. Mass spectrogram of the 6B from the aqueous phase HDO of $6 \mathrm{~A}$. 


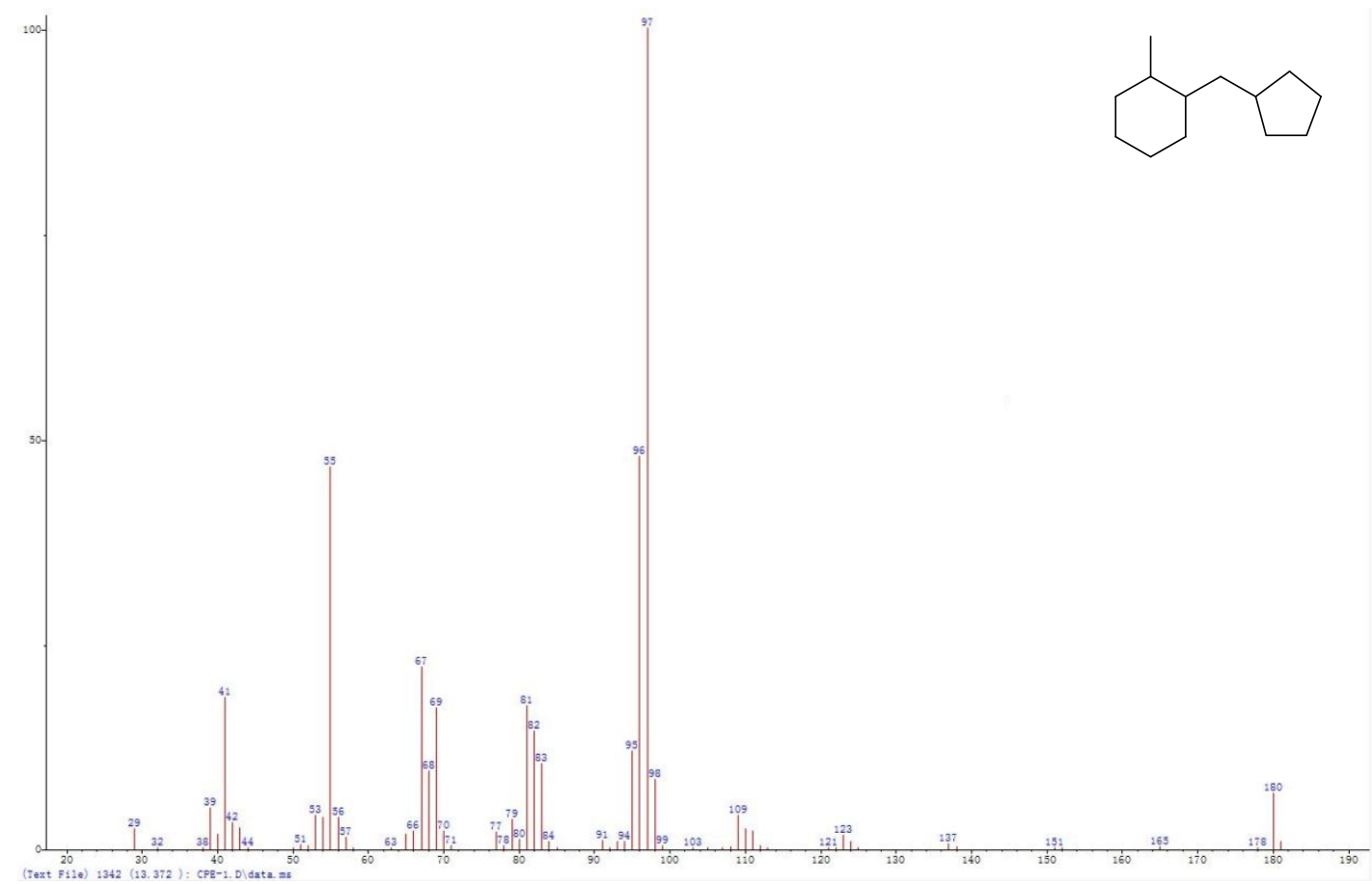

Figure S38. Mass spectrogram of the $\mathbf{6 C}$ from the aqueous phase HDO of $6 \mathrm{~A}$. 


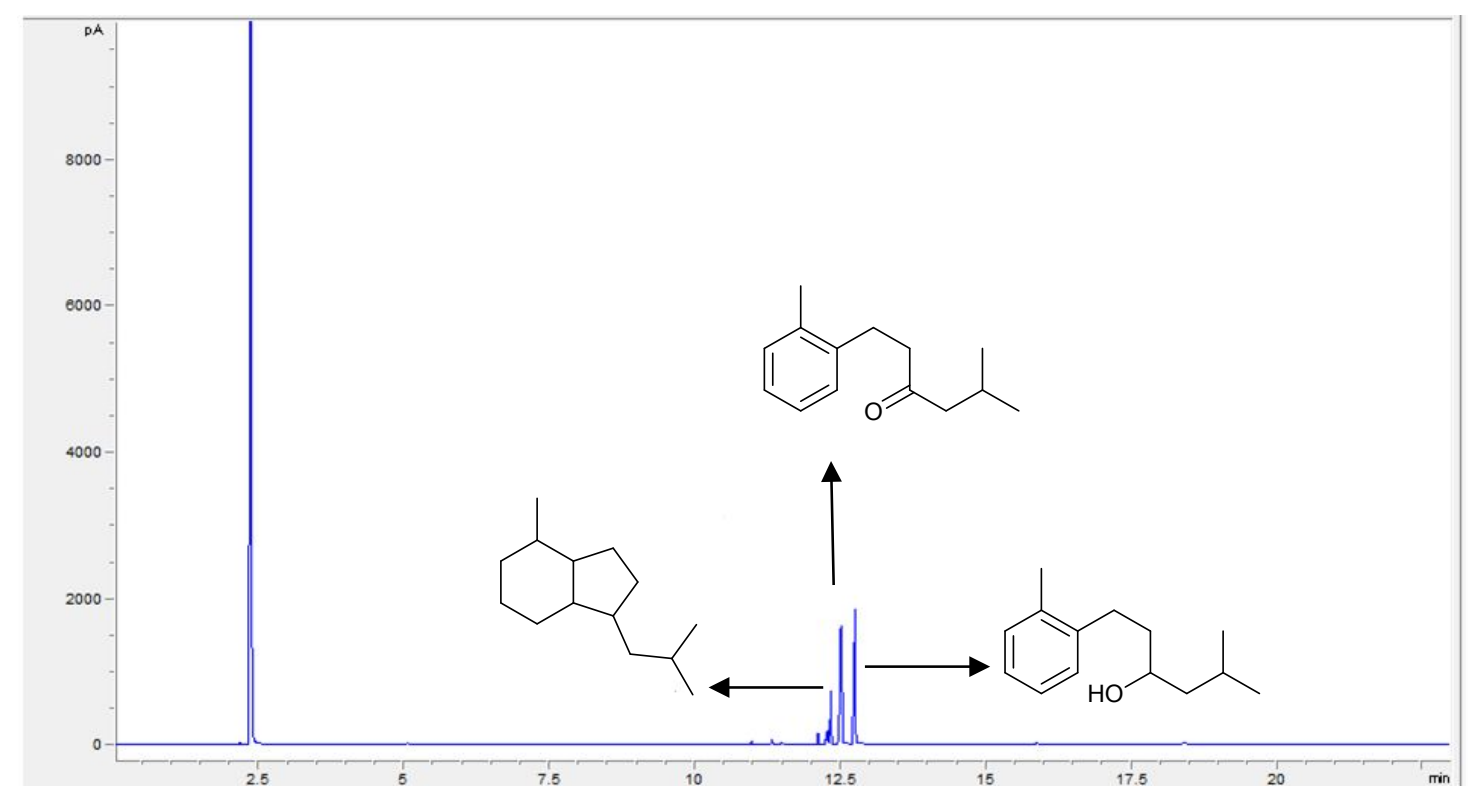

Figure S39. Gas chromatogram of the aqueous phase HDO product of 1A. Reaction conditions: $10 \mathrm{mmol} \mathrm{1A,} 0.1 \mathrm{~g} \mathrm{Pt} / \mathrm{C}, 50 \mathrm{~mL} \mathrm{H} \mathrm{O}_{2}$; $6 \mathrm{MPa} \mathrm{H}$, $383 \mathrm{~K}, 20 \mathrm{~min}$. 

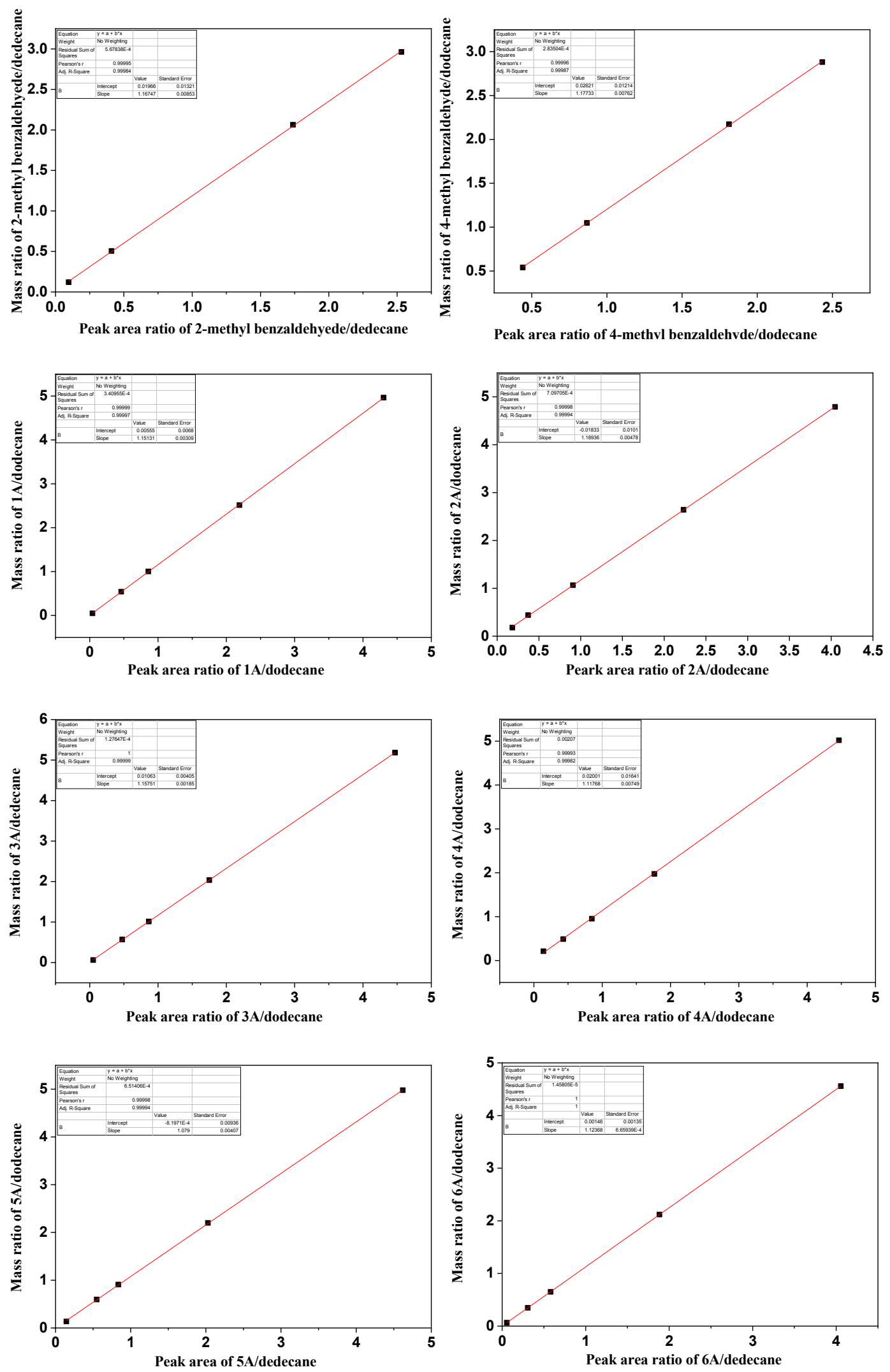

Figure S40. Calibration curves for calculation the mass of 2-methyl benzaldehyde,

4-methyl benzaldehyde, $1 \mathrm{~A}, \mathbf{2 A}, \mathbf{3 A}, \mathbf{4 A}, \mathbf{5 A}, \mathbf{6 A}$ in the aldol condensation products. 


\section{Reference}

(1) Deng, Q.; Nie, G.; Pan, L.; Zou, J.-J.; Zhang, X.; Wang, L., Highly selective self-condensation of cyclic ketones using MOF-encapsulating phosphotungstic acid for renewable high-density fuel. Green Chem. 2015, 17, 4473-4481, Doi:10.1039/c5gc01287b.

(2) Sheng, X.; Li, G.; Wang, W.; Cong, Y.; Wang, X.; Huber, G. W.; Li, N.; Wang, A.; Zhang, T., Dual-bed catalyst system for the direct synthesis of high density aviation fuel with cyclopentanone from lignocellulose. AIChE J. 2016, 62, 2754-2761, Doi:10.1002/aic.15248.

(3) Tang, H.; Chen, F.; Li, G.; Yang, X.; Hu, Y.; Wang, A.; Cong, Y.; Wang, X.; Zhang, T.; Li, N., Synthesis of jet fuel additive with cyclopentanone. J. Energy Chem. 2019, 29, 23-30, Doi:10.1016/j.jechem.2018.01.017.

(4) Xu, J.; Li, N.; Li, G.; Han, F.; Wang, A.; Cong, Y.; Wang, X.; Zhang, T., Synthesis of high-density aviation fuels with methyl benzaldehyde and cyclohexanone. Green Chem. 2018, 20, 3753-3760, Doi:10.1039/C8GC01628C. 